\title{
Three-Dimensional Printing Strategies for Irregularly Shaped Cartilage Tissue Engineering: Current State and Challenges
}

\author{
Hui Wang ${ }^{1}$, Zhonghan Wang ${ }^{1}$, He Liu ${ }^{1}$, Jiaqi Liu ${ }^{1}$, Ronghang $L i^{1}$, Xiujie Zhu ${ }^{1}$, Ming Ren ${ }^{1}$, \\ Mingli Wang ${ }^{1}$, Yuzhe Liu ${ }^{1}$, Youbin $\mathrm{Li}^{1}$, Yuxi Jia ${ }^{1 *}$, Chenyu Wang ${ }^{2 *}$ and Jincheng Wang ${ }^{1 *}$ \\ ${ }^{1}$ Orthopaedic Medical Center, The Second Hospital of Jilin University, Changchun, China, ${ }^{2}$ Department of Plastic and \\ Reconstructive Surgery, The First Hospital of Jilin University, Changchun, China
}

\section{OPEN ACCESS}

Edited by:

Laura Creemers,

University Medical Center Utrecht,

Netherlands

Reviewed by:

Pinar Yilgor Huri,

Ankara University, Turkey

Menekse Ermis Sen,

Terasaki Institute for Biomedical

Innovation, United States

*Correspondence:

Yuxi Jia

jiayuxi@jlu.edu.cn

Chenyu Wang

wangchenyu@jlu.edu.cn

Jincheng Wang

wangjinc@jlu.edu.cn

Specialty section:

This article was submitted to Tissue Engineering and Regenerative

Medicine,

a section of the journal

Frontiers in Bioengineering and

Biotechnology

Received: 14 September 2021

Accepted: 07 December 2021

Published: 05 January 2022

Citation:

Wang H, Wang Z, Liu H, Liu J, Li R, Zhu X, Ren M, Wang M, Liu Y, Li Y,

Jia $Y$, Wang $C$ and Wang J (2022)

Three-Dimensional Printing Strategies for Irregularly Shaped Cartilage Tissue

Engineering: Current State

and Challenges.

Front. Bioeng. Biotechnol. 9:777039.

doi: 10.3389/fbioe.2021.777039
Although there have been remarkable advances in cartilage tissue engineering, construction of irregularly shaped cartilage, including auricular, nasal, tracheal, and meniscus cartilages, remains challenging because of the difficulty in reproducing its precise structure and specific function. Among the advanced fabrication methods, three-dimensional (3D) printing technology offers great potential for achieving shape imitation and bionic performance in cartilage tissue engineering. This review discusses requirements for $3 \mathrm{D}$ printing of various irregularly shaped cartilage tissues, as well as selection of appropriate printing materials and seed cells. Current advances in 3D printing of irregularly shaped cartilage are also highlighted. Finally, developments in various types of cartilage tissue are described. This review is intended to provide guidance for future research in tissue engineering of irregularly shaped cartilage.

Keywords: 3D printing, cartilage tissue engineering, irregularly shaped cartilage, shape imitation, bionic performance

\section{INTRODUCTION}

Cartilage is widely distributed throughout the human body, and is mainly composed of extracellular matrix (ECM) with embedded chondrocytes (Anderson, 1962). The morphologies of the auricle, nose, trachea, and meniscus are irregular. The shape of cartilage varies, often forming irregular arcs or circular patterns depending on its function. These functions include maintaining the specific shape of a tissue or buffering mechanical forces that deform tissues during movement (Honkanen et al., 2016; Zhou et al., 2018). Due to a lack of blood perfusion, cartilage cannot be repaired as easily as other injured structures such as skin and bone that contain blood vessels. Current strategies for restoring damaged cartilage that is irregularly shaped have not met the initially high expectations (Le et al., 2020). For 3D printing of irregularly shaped cartilage, the challenges are specific to each structure.

For repair of auricular and nasal cartilage where aesthetic appearance is the primary consideration, modified autologous costal cartilage is commonly used for transplantation (Foerster, 1966a; Vuyk and Adamson, 1998). However, autologous transplantation may cause damage to the donor site, and patients are often unsatisfied with the appearance of the reconstructed area. In addition, there is a risk of postoperative complications such as infection (Thorne et al., 2001; Yamada, 2018). As an alternative to autologous implantation, commercial auricular prostheses are also a rational choice as they involve pre-assembled scaffolds with $\mathrm{C}$ - and $\mathrm{Y}$-shaped frames made of 
composite porous polyethylene (Medpor) material (Cenzi et al., 2005). However, surgical implantation is often accompanied by complications like erosion, infection, absorption collapse, inflammation, and displacement (Younis et al., 2010). Furthermore, this treatment is only applicable to total replacement of the auricular scaffold, which is not appropriate for repair of local auricle defects (Yamada, 2018).

Nasal prostheses are not only used in repair of nasal cartilage defects caused by congenital diseases and trauma but also in rhinoplasty. Nasal septal cartilage, auricular cartilage, and alar cartilage are often used as grafts during autogenous cartilage transplantation. Bone grafting can also be used in rhinoplasty, but it is important not to ignore the side effects of rhinoplasty or complications such as open roof, stairstep, and rocker deformities, bony pyramid and nostril asymmetries, and limited donor sites (Vuyk and Adamson, 1998). The trachea and meniscus function in load bearing and supporting, which is difficult to restore following injury due to a lack of blood vessels (Fabre et al., 2013). In this case, the size and shape of the implanted scaffold can be customized with the aid of software according to the patient's needs. In addition, incorporation of acellularized hydrogels into a scaffold can promote biocompatibility after implantation (Mouser et al., 2020).

Taken together, the lack of suitable repair materials of proper morphology, hardness, and biocompatibility is a major problem in cartilage defect repair, and $3 \mathrm{D}$ printing has come to the forefront of cartilage tissue engineering to address these problems. In 1986, 3D printing technology was introduced to the public (Hull, 1996). Among 3D printing technologies, fused deposition modeling (FDM) involves melting a polymer so that it flows through a nozzle, allowing the scaffold to be suitably shaped as it is printed layer by layer (Penumakala et al., 2020). In order to construct 3D tissues, 3D bioprinting was developed to build complex structures by incorporating cells and growth factors into a hydrogel and extruding the composite material layer by layer according to a pre-designed 3D model (Gu et al., 2016; Fenton et al., 2019; Mouser et al., 2020) (Scheme 1). In addition to precise control of scaffold shape, spatial resolution and mechanical properties can be controlled during 3D printing (Mouser et al., 2017).

This review summarizes studies of $3 \mathrm{D}$ printing of irregularly shaped cartilage scaffolds and discusses the current status of that research, including the use of common materials, cells, and related 3D printing technologies (Scheme 2). The intend of this review is to provide guidance for future research on irregularly shaped cartilage in tissue engineering.

\section{MATERIALS USED FOR 3D BIO-PRINTED IRREGULARLY SHAPED CARTILAGE}

3D printing technology has the potential to fundamentally enhance regenerative medicine (Rajabi et al., 2021). Several studies of $3 \mathrm{D}$ printing of irregularly shaped cartilage have reported the use of high molecular weight polymers, including poly (lactic-co-glycolic acid) (PLGA) (Wei P. et al., 2020), poly (lactic acid) (PLA) (Rosenzweig et al., 2015), poly (ع-caprolactone) (PCL) (Xu et al., 2019; Li et al., 2021), and polyurethane (PU) (Kim H. Y. et al., 2019), to print cartilage scaffolds that are stable due to their optimal mechanical properties. In addition, depending on the experimental requirements, hydrogels with good biocompatibility such as silk fibroin (SF) (Rosadi et al., 2019), alginate, gelatin (Yang et al., 2019), and chitosan (CS) are often chosen as printing materials or used as part of a cartilage scaffold. Such hydrogels can act as a cell matrix to support cell growth (Unagolla and Jayasuriya, 2020). The following sections describe each material in detail.

\subsection{Synthetic Macromolecular Polymer Materials}

\subsubsection{Poly(Lactic-co-Glycolic Acid)}

PLGA possesses ideal bio-compatibility and bio-degradation properties. PLGA is approved by the U.S. Food and Drug Administration for clinical applications, including drug synthesis and prosthesis fabrication (Gentile et al., 2014). PLGA is a type of thermoplastic, and its melting temperature is $190^{\circ} \mathrm{C}$, which eliminates the possibility of printing PLGA with living cells (Kim et al., 2016). The characteristics of PLGA are determined by its molecular weight, the type of end caps, and the lactic acid (LA)/glycolic acid (GA) ratio. PLGA with an ester end cap is more stable during printing and degrades more slowly. In contrast, PLGA degradation is accelerated by an acid end cap. PLGA viscosity increases with increasing LA/GA ratio. Hence a PLGA scaffold with a higher LA/GA ratio and ester end cap is more suitable for preparation of cartilage scaffolds (Guo et al., 2017; Gradwohl et al., 2021). In addition, PLGA is also used to make electrospun scaffolds. Due to the bridging and pull-out properties of PLGA, materials mixed with PLGA may exhibit ductile fracture during bioprinting (Zhao G. et al., 2020).

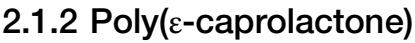

PCL is a polymer obtained by ring-opening polymerization of $\varepsilon$-caprolactone monomers (Bhattacharjee et al., 2021). The compressive modulus of pure PCL is approximately $4.5 \mathrm{MPa}$, which is significantly lower than that of PLA and other materials (Popescu et al., 2018). Nevertheless, the elastic modulus of the PCL is about $30 \mathrm{MPa}$, which is closer to that of native cartilage and makes it more suitable for $3 \mathrm{D}$ printing of cartilage (Zhang et al., 2017). The low melting point of PCL $\left(55^{\circ} \mathrm{C}\right)$ renders it easier to extrude in $3 \mathrm{D}$ printing (Dong et al., 2017). Owing to a low glass transition temperature and high thermal stability, PCL has great potential for tissue engineering (Chia and Wu., 2015). PCL can be fabricated into a scaffold by selective laser sintering (SLS) (Patel et al., 2015) and direct ink writing (Zhang et al., 2020). Because high temperature can damage cells, PCL with a lower melting point is more appropriate for acting as a protective layer on bioactive scaffolds (Kim et al., 2016).

\subsubsection{Poly(Lactic Acid)}

PLA is a type of thermoplastic polymer made from natural renewable resources, and is biodegradable (Wang et al., 2015). 


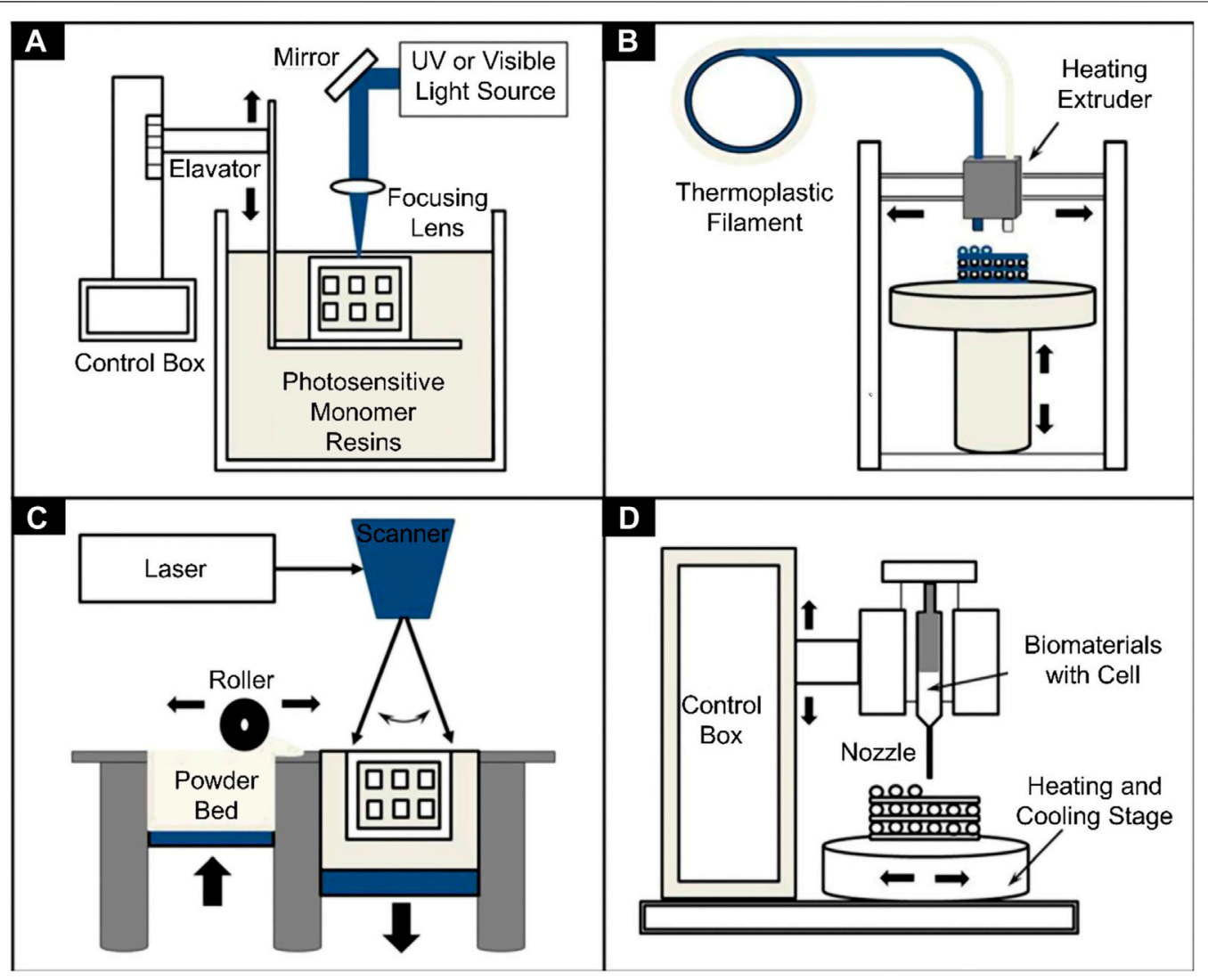

SCHEME 1 | Schematics of different 3D bioprinters used in tissue engineering. (A) Vat photopolymerization, (B) Fused filament fabrication, (C) Selective laser sintering, and (D) Inkjet 3D printing (Gu et al., 2016).

PLA can be processed into orthopedic implant materials by FDM, SLS stereolithography (SLA), and other 3D printing technologies (Van den Eynde and Van Puyvelde, 2018; Chen $\mathrm{X}$. et al., 2019). When the temperature rises to $41.5^{\circ} \mathrm{C}$, the DNA of cells will be damaged and the cells will die (Akihisa et al., 2004). The high temperature required for printing PLA harms cells seeded onto the surface of the scaffold, but printing PCL between two layers of PLA will make the cell mortality reduce since the melting point of PCL is $60^{\circ} \mathrm{C}$. Heated PLA is continuously extruded into three layers by a nozzle, and layers of PCL are extruded between them. Cells encapsulated in sodium alginate are then deposited in the resulting space (Kim et al., 2016). Moreover, printing of scaffolds using layerby-layer printing technology can improve survival of cells in hydrogel scaffolds (Baena et al., 2019).

When PLA and PCL are used together to prepare 3D-printed scaffolds, not only is cell damage reduced but scaffold mechanical properties are improved. When a PLA mesh covers the surface of a PCL scaffold, its strength significantly increases (Pensa et al., 2019). PLA can be added to a variety of polymers used in 3Dprinting. It can also be modified to form poly (L-lactic acid) (PLLA) and poly (D-lactic acid) (PDLA) polymers by incorporating enantiomeric L- and D-lactic acid units, respectively (Masutani and Kimura, 2017). In addition, the toughness of PLLA can be increased by adding PCL to form poly (l-lactide-co-e-caprolactone) (PLCL) (Liu W. et al., 2020).

\subsubsection{Polyurethane}

PU is usually made from a combination of diisocyanate and polyol (Wang P. et al., 2019), and can be divided into two forms: thermosetting and thermoplastic (Griffin et al., 2020), both of which have good biocompatibility. Compared with other materials, PU has higher elasticity and tensile strength (Griffin et al., 2020). In addition, PU is thermally sensitive and exhibits a sol-gel transition at $37^{\circ} \mathrm{C}$ (Hsieh and Hsu., 2015). As a result, it has been used to fabricate scaffolds in some soft tissue engineering experiments (Luo K. et al., 2020; Farzan et al., 2020). PU is widely used in various fields of 3D printing by way of fused fiber fabrication (FFF), bio-plotting, SLA (Griffin et al., 2020), and FDM (Xiao and Gao., 2017). The tensile strength and break elongation of thermoplastic polyurethane (TPU) scaffolds printed by FDM can reach $46.7 \mathrm{MPa}$ and $702 \%$, respectively, by arranging the fiber at a $45^{\circ}$ angle and forming the scaffold at $215^{\circ} \mathrm{C}$ (Xiao and Gao., 2017). 3D-printed scaffolds made of PU have excellent shape memory. In addition, they are biodegradable and osteogenic (Wang et al., 2018). Moreover, PU has been used in research on $3 \mathrm{D}$ printing of tendons. Scaffolds have been successfully 


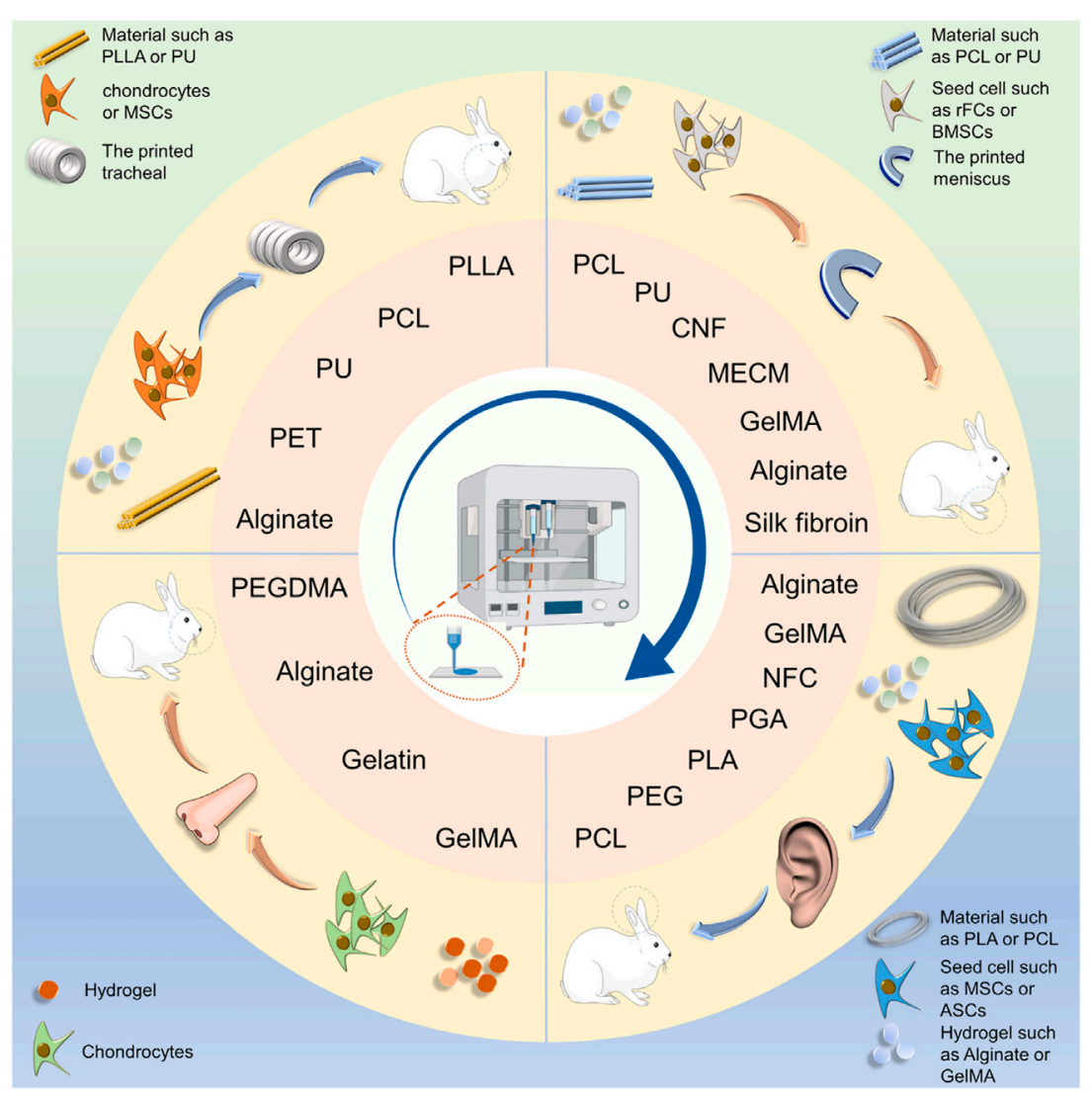

SCHEME 2 | Schematic illustration of scaffold fabrication for cartilage engineering of the auricle, nasal cartilage, trachea, and meniscus. Polymers and hydrogel were made into irregularly shaped cartilage scaffolds using 3D printing technology. PLLA, poly(L-lactic acid); PCL, Poly( $\varepsilon$-caprolactone); PU: Polyurethane; PEG, polyethylene glycol; PEGDMA, polyethylene glycol dimeth-acrylate; PGA, polyglycolic acid; NFC, nanofiber cellulose; MECM, meniscus extracellular matrix.

printed by combining the advantages of PU and PCL (Merceron et al., 2015).

\subsection{Natural Materials \\ 2.2.1 Silk Fibroin}

$\mathrm{SF}$ is a natural material extracted from silkworm cocoons. It is biodegradable and is widely used in medical fields. To date, SF has been used with $3 \mathrm{D}$ printing technology to repair defects in skin, bone, cartilage, and vascular tissues (Wang Q. et al., 2019). Pure SF has relatively poor mechanical strength, so it is often mixed with other materials such as hydroxypropyl methylcellulose, gelatin, PEG, and glycerol to improve its properties (Mu et al., 2020). The mixture of SF and hydroxy propyl methyl cellulose of methacrylate (HPMC-MA) has excellent mechanical properties that depend on methacrylate content. The compressive stress of the mixture is $25 \mathrm{KPa}$ (Ni et al., 2020). In addition, the mechanical properties of silk fibroin scaffolds were improved by the technology of biomineralization and pre-mineralization (Neubauer et al., 2021). Biomineralization is the process of metabolizing cells to form minerals (Neubauer and Scheibel, 2020). Graphene oxide, $\beta$ - Tricalcium phosphate, and nano hydroxyapatite can be added to silk fibroin fibers to premineralize silk fibroin (Liu F. et al., 2020; Wang L. et al., 2020;
Zafar et al., 2020). Except for the improvement of mechanical properties, the viscosity of the mixture made of silk fibroin and gelatin will be improved after tyrosinase induced crosslinking (Chameettachal et al., 2016).

In addition to common chemical cross-linking methods, SF can also be cross-linked by physical methods to improve its mechanical properties (Chi et al., 2018). Cartilage acellular matrix (CAM) has properties suitable for cell growth, but its extrusion properties are unsuitable for printing. The addition of SF endows CAM with a fluidity that makes it suitable as a bio-ink for 3D printing (Chi et al., 2018). A solution with useful nanostructural and mechanical properties can be prepared by dissolving $\mathrm{SF}$ in a $\mathrm{CaCl}_{2}$ formic acid solution. The maximum elastic modulus and final tensile strength of the stretched SF film in the dry state are $4 \mathrm{GPa}$ and $106 \mathrm{MPa}$, respectively (Zhang et al., 2015).

\subsubsection{Alginate}

Alginate can be used in various fields, including wound healing, drug delivery, and tissue engineering (Liu et al., 2019; Wei X. et al., 2020; Oveissi et al., 2020; Khoshnood et al., 2021). Alginate is usually extracted from brown algae and possesses excellent biocompatibility. $\mathrm{Ba}^{2+}$ or $\mathrm{Ca}^{2+}$ salts can rapidly cross-link sodium 
alginate sol into a gel state (Zhang et al., 2019). It has been shown that cell activity in a ring scaffold cross-linked by $\mathrm{BaCl}_{2}$ is stronger than when cross-linked by $\mathrm{CaCl}_{2}$ (Dranseikiene et al., 2020). Cross-linking alginate can also increase its mechanical strength, which provides it with many applications in tissue engineering. Alginate gel is commonly used in $3 \mathrm{D}$ printing as it has favorable rheological properties (Kim M. H. et al., 2019). Sodium alginate gels mixed with gelatin to form a hybrid bio-ink possess improved viscosity and elasticity (Cheng et al., 2019; Liu et al., 2019; Soltan et al., 2019). The low degradation rate of alginate gel scaffolds make them poor implants for tissue regeneration. However, using gamma rays to change the molecular weight distribution can accelerate degradation of sodium alginate gels (Kong et al., 2004).

The mechanical strength of an alginate gel is quite low. Mixing PEG and sodium alginate produces a gel with high mechanical strength that is suitable for growth of human bone marrow mesenchymal stem cells (Melo et al., 2019). The rheological properties of alginate gel-based inks influence the shape fidelity and resolution of the printed structure, and they can be improved by mixing alginate gel with carrageenan hydrogels (Kim M. H. et al., 2019). A set of experimental studies has shown that the rheology (viscosity) of the bioprinting ink formed by mixing alginate gel with gelatin is dependent on the printing temperature (Liu et al., 2019). For cells mixed into the hydrogel, adhesion to the gel polymer is essential, and alginate gel modified by dopamine can significantly strengthen cell adhesion (Luo et al., 2019).

\subsubsection{Gelatin}

Gelatin is a water-soluble and biodegradable polypeptide produced by hydrolysis of collagen. Its enzyme degradation rate is unsatisfactory and it has poor mechanical stability, which limits its applications in biological tissue engineering (Raucci et al., 2019). However, combining gelatin with other materials can improve its viscosity and make it more suitable for 3D printing (Duan et al., 2013; Unagolla and Jayasuriya, 2020). Bio-inks containing gelatin exhibit good fluidity at $35^{\circ} \mathrm{C}$, which is conducive to extrusion during $3 \mathrm{D}$ printing. After cooling down on the casting platform at $4^{\circ} \mathrm{C}$, the scaffold solidifies rapidly (Dutta et al., 2021). In cartilage tissue engineering, MMP2 activity can be induced by gelatin to degrade the synthetic matrix. Then a pericellular zone is formed to accumulate extracellular matrix growth factors and the newly synthesized matrix, so as to the differentiation of chondrocyte is promoted (Chameettachal et al., 2016).

\subsubsection{Chitosan}

CS is prepared by alkaline deacetylation of chitin. CS has many desirable properties such as natural non-toxicity, histocompatibility, biodegradability, and antibiosis (Long et al., 2019). A fluid suitable for extrusion printers can be prepared by dissolving CS in acid solutions such as GA and LA. A solution made by dissolving CS in $30 \mathrm{wt} \% \mathrm{GA}$ is suitable for preparation of CS catheters and 3D printing as its tensile strength and Young's modulus are $10.98 \pm 0.61 \mathrm{MPa}$ and $12.38 \pm 1.19 \mathrm{MPa}$, respectively (Zhao C. Q. et al., 2020). CS can also be used to improve the performance of other scaffolds. Adhesion of calcium phosphate to PLA can be increased by adding a layer of CS gel to a PLA scaffold, which also improves the mechanical properties of the scaffold (Schneider et al., 2018). Combining CS with mixtures that contain PLA can make the material more hydrophilic (Cheng and Chen, 2017). CS mixed with saline alginate gel can increase its viscosity, making it more suitable for 3D printing (Liu et al., 2018).

\section{SEED CELLS USED FOR 3D BIO-PRINTED IRREGULARLY SHAPED CARTILAGE}

Depending on the specific requirements, the best biomimetic effect can be achieved by including materials such as seed cells (Kačarević et al., 2018; Zhang and Song, 2018), and selection of an optimal seed cell is of vital importance to achieve cartilage regeneration. Chondrocytes and mesenchymal stem cells (MSCs) are commonly used in cartilage tissue engineering research.

Chondrocytes are often chosen as seed cells, but the tissue sites for obtaining them are limited and vulnerable to injury. Chondrocytes used in cartilage tissue engineering have low immunogenicity, but isolation methods are complex and less well developed than those for MSCs (Francis et al., 2018a)-and considering their multi-directional differentiation potential, MSCs are often preferred (Aggarwal and Pittenger., 2005). In addition, MSCs can inhibit inflammation in scaffolds implanted in vivo, and reduce damage resulting from foreign body reactions (Ding et al., 2016).

Some types of MSCs can differentiate toward cartilage cells. Among types of MSCs, bone marrow stem cells (BMSCs) are commonly used in cartilage tissue engineering. As the first identified mesenchymal stem cells, there are many studies on BMSCs (Strioga et al., 2012). BMSCs have the advantage of being plentiful and easy to obtain (Wang Y.-H. et al., 2020), and they have the ability to differentiate toward ecto-, meso-, and endodermal cell lineages, including adipocytes, germ cells, chondrocytes, osteoblasts, pancreatic islet-like cells, hepatocytes, myocytes, annulus fibrosus-like cells, and neuronlike cells (Li et al., 2018). However, BMSCs collected from the elderly are not entirely suitable owing to their limited ability to differentiate and low rate of proliferation (Pittenger et al., 1999; Zaim et al., 2012). There is still a great deal of controversy concerning selection of stem cells. Compared with BMSCs, adipose-derived mesenchymal stem cells (ADSCs) are more plentiful and easier to obtain (Ra et al., 2011; Jo et al., 2014). ADSCs have the potential to differentiate into mesoderm tissue lineages, including bone, cartilage, fat, and muscle (Francis et al., 2018b). Studies have shown that ADSCs are more likely to differentiate into cartilage than are BMSCs (Jang et al., 2015). Umbilical cord blood mesenchymal stem cells (UCB-MSCs) have a greater ability to differentiate into cartilage and express proteins and cytokines than do BMSCs (Lo et al., 2013). However, using BMSCs as seed cells is more conducive to collagen formation and cartilage repair (Contentin et al., 2019). Nevertheless, these conclusions are influenced by the different evaluation criteria 
TABLE 1 | Summary of 3D-printed auricular cartilage.

\begin{tabular}{|c|c|c|c|c|}
\hline Material & Seed cells & $\begin{array}{l}\text { Bioprinting } \\
\text { Technology }\end{array}$ & Key point & References \\
\hline $\begin{array}{l}\text { Nanofibrillated cellulose (NFC)/ } \\
\text { Alginate hydrogels }\end{array}$ & $\begin{array}{l}\text { Human nasoseptal chondro- } \\
\text { cytes (hNC) }\end{array}$ & Extrusion printing & $\begin{array}{l}\text { The hybrid bio-ink, mixed at an } 80: 20 \text { ratio of NFC } \\
\text { to alginate, is printed by an extrusion printer }\end{array}$ & $\begin{array}{l}\text { Markstedt et al. } \\
\text { (2015) }\end{array}$ \\
\hline PCL/PEG/Alginate hydrogels & $\begin{array}{l}\text { Human adipose derived stem } \\
\text { cells (ASCs) }\end{array}$ & Extrusion printing & $\begin{array}{l}\text { PEG and PCL were used as the sacrificial and } \\
\text { main materials of the framework }\end{array}$ & Lee et al. (2014) \\
\hline $\begin{array}{l}\text { PCL/methacrylate Gelatin (GelMA)/ } \\
\text { Hyaluronic acid (HAMA)/Pluronic F- } \\
127 \text { hydrogel }\end{array}$ & $\begin{array}{l}\text { Bone marrow-derived human } \\
\text { (BMSCs) Mesenchymal stem } \\
\text { cells (MSCs) }\end{array}$ & Extrusion printing & $\begin{array}{l}\text { PCL and GelMA-HAMA were used for hybrid } \\
\text { printing, Pluronic F-127 was selected as a } \\
\text { sacrificial material }\end{array}$ & $\begin{array}{l}\text { Chung et al. } \\
(2020)\end{array}$ \\
\hline Type I collagen gel/PCL & Porcine auricular cartilage & $\begin{array}{l}\text { EOS P100 laser } \\
\text { sintering system }\end{array}$ & $\begin{array}{l}\text { The cells were embedded in collagen I gel solution } \\
\text { and the cell suspension was then pipetted into the } \\
\text { PCL scaffolds }\end{array}$ & $\begin{array}{l}\text { Zopf et al. } \\
(2015)\end{array}$ \\
\hline PU & $\begin{array}{l}\text { Tonsil-derived mesenchymal } \\
\text { stem cells }\end{array}$ & - & $\begin{array}{l}\text { 3D printing of auricular cartilage scaffold was } \\
\text { performed with PU material }\end{array}$ & $\begin{array}{l}\text { Kim et al. } \\
\text { (2019a) }\end{array}$ \\
\hline PCL & - & $\begin{array}{l}\text { Fused deposition } \\
\text { system }\end{array}$ & $\begin{array}{l}\text { Creating auricular model and } 3 \mathrm{D} \text { printing with } \mathrm{PCL} \\
\text { material }\end{array}$ & $\begin{array}{l}\text { Jung et al. } \\
\text { (2019) }\end{array}$ \\
\hline PCL/PGA/PLA & Picrotia chondrocytes (MCs) & $\begin{array}{l}\text { Fused deposition } \\
\text { system }\end{array}$ & $\begin{array}{l}\text { The auricular scaffold used PCL as an inner core, } \\
\text { which was wrapped with PGA unwoven fibers and } \\
\text { coated with PLA. }\end{array}$ & $\begin{array}{l}\text { Zhou et al. } \\
\text { (2018) }\end{array}$ \\
\hline $\begin{array}{l}\text { Gelatin/fibrinogen/hyaluronic acid } \\
(\mathrm{HA}) / \text { glycerol/PCL/Pluronic F-127 } \\
\text { hydrogel }\end{array}$ & 3T3 fibroblasts & $\begin{array}{l}\text { An integrated } \\
\text { tissue-organ printer } \\
\text { (ITOP) }\end{array}$ & $\begin{array}{l}\text { 3T3 cells were mixed in the prepared hydrogel, the } \\
\text { auricular scaffold structure was printed } \\
\text { simultaneously with PCL, and Pluronic F-127 } \\
\text { hydrogel was used to print the sacrificial layer to } \\
\text { maintain scaffold structure }\end{array}$ & $\begin{array}{l}\text { Kang et al. } \\
(2016)\end{array}$ \\
\hline
\end{tabular}

used, and therefore the choice of MSC depends on the purpose of the experiment. It has been shown that a mixture of ADSCs and chondrocytes can be used for seeding cells onto a biodegradable scaffold (Morrison et al., 2018).

\section{3D-PRINTED IRREGULARLY SHAPED CARTILAGE SCAFFOLDS}

The structural complexity of irregularly shaped cartilage increases the difficulty of manufacturing scaffolds. However, the emergence of $3 \mathrm{D}$ printing technology provides a new solution for repair of irregularly shaped cartilage. On this basis, and considering the biocompatibility of materials and selection of seed cells, useful improvements have been made that are adapted to the specific requirements of different structures to facilitate study of $3 \mathrm{D}$ printing of irregularly shaped cartilage. This section summarizes progress in $3 \mathrm{D}$ printing technology used for reconstruction of four types of irregularly shaped cartilage: auricular, nasal, tracheal and meniscus.

\subsection{D-Printed Auricular Cartilage Tissue}

Developments in medical procedures and knowledge have facilitated surgical repair or improvements of features that affect facial beauty. There is a long history of research on auricular repair, including treatment of mild injuries such as earlobe and earring injury, and severe injuries such as when the entire auricle is bitten or cut (Song et al., 2020). Because the auricle is an important facial feature, congenital auricle deformity or injury can damage mental health. 3D-printed auricular cartilage can be used for auricle shape reconstruction. The first step in $3 \mathrm{D}$ printing of an auricle is to design its shape, and one of two methods involving CAD software is typically used: either import DICOM files to synthesize auricle shape, or design the required graphics directly (Zhou et al., 2018). The resulting auricle model then needs to be converted into STL (structured template language) form. An iTOP (integrated tissue and organ printer) can also be used to print the ideal ear shape (Kang et al., 2016). Currently there are two main types of 3D-printed auricle scaffold. In the first, the auricle shape is printed directly using hydrogel, and in the second, the support structure of the auricular scaffold is first printed using biomaterials, and then the surface of the scaffold is covered by a cell-containing hydrogel using 3D printing or immersing the scaffold into the hydrogel (Jang et al., 2020).

\subsubsection{Preparation of Auricular Scaffolds Using Hydrogel}

Because of the pretty biocompatibility of hydrogels, some studies have been devoted to research on $3 \mathrm{D}$ printing of auricular scaffolds using hybrid hydrogels. Bio-ink produced by mixing gelatin with SF from two sources (Philosamia ricini and Bombyx mori) can be used to print auricular cartilage as it gels without cross-linking (Singh et al., 2019), which eliminates potential side effects of the cross-linker. This material shows excellent fidelity, stability, swelling properties, biodegradability, and promotes cell viability (Singh et al., 2019). In addition, a hybrid bio-ink can be photocured during 3D printing by adding methacrylic anhydride and a photoinitiator in a mixture of gelatin and hyaluronic acid. Scaffold degradation becomes prolonged after being freeze-dried, and the compression strength of lyophilized scaffolds is significantly greater than for other scaffolds. This cross-linking method allows sufficient time for preparation of composite materials and development of chondrocytes (Xia et al., 2018). 

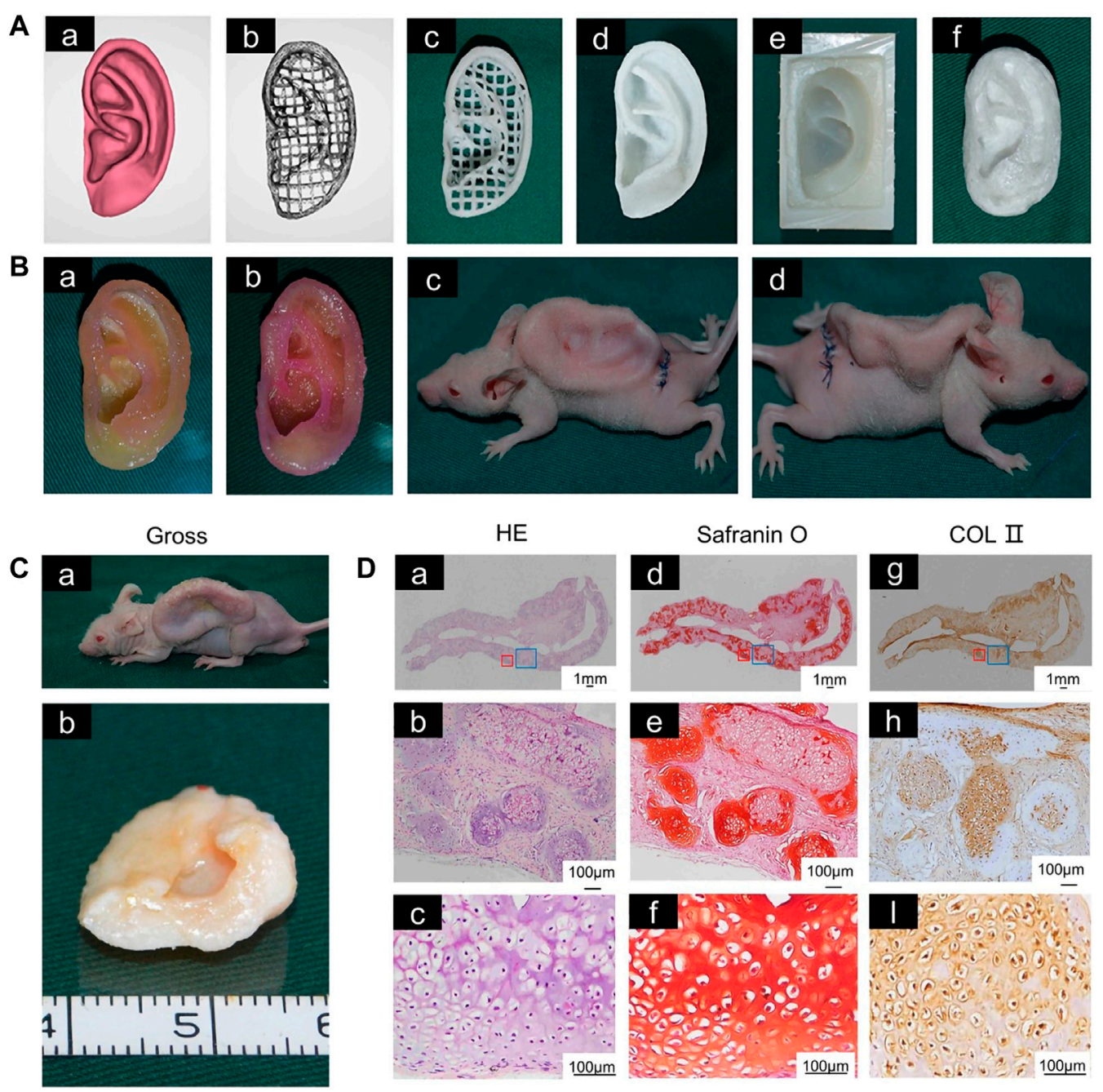

FIGURE 1 |3D-printed auricular scaffold and in vivo experiments. (A) Design of a 3D-printed auricle model and the resulting printed scaffold; (a) 3D digital model of the human auricle, (b) 3D mesh digital model, (c) PCL inner core, (d) human auricle-shaped PCL positive mold, (e) silicone casting mold, and (f) ACM/Gelatin-PCL scaffold. (B) Auricular scaffold before implantation and after implanting it into a nude mouse for 2 weeks. (C) Images of scaffolds cultured in vivo for 12 weeks. (D) H\&E and safranin-O staining showed lacunar structure and cartilage-specific ECM deposition (Jia et al., 2020).

Although freeze-drying results in some improvement in the mechanical properties of hydrogel scaffolds, it remains to be seen whether they remain stable as the gel degrades.

\subsubsection{Preparation of Auricular Scaffolds With Polymer Materials and Hydrogel}

The other kind of 3D-printed auricular cartilage is that made of composite polymer materials and hydrogel. Polymers such as PLA, PCL, and hydrogels are often combined to fabricate auricular scaffolds (Table 1). PCL material is often preferred for auricular cartilage scaffold printing because of its high compression modulus (Olubamiji et al., 2016). The compression modulus of the scaffold is affected by the properties of the material and the diameter of the scaffold, which are related to printing speed. For a given flow rate through the printer nozzle, the higher the printing speed, the smaller the diameter of the extruded stream, which alters the mechanical properties of the printed material. The compression modulus of the PCL scaffold decreases with increasing nozzle diameter, and its flexibility is affected by line spacing and angle. Running the $3 \mathrm{D}$ printer nozzle along the $0^{\circ} / 45^{\circ}$ direction to print the scaffold will make the scaffold more flexible (Chung et al., 2020). Experimental studies have shown that scaffolds printed with PCL and hydrogel mixed with cells are more conducive to cartilage formation than if the cells are placed on the surface of the composite scaffold (Park et al., 2017).

For the auricular scaffolds printed with PCL, the shape of the pores in the scaffold can affect the cells seeded into it. Spherical pore design not only facilitates chondrocytes adopting a shape characteristic of natural cartilage in vivo but also accelerates matrix deposition (Zopf et al., 2018). However, incorporation of hydrogel into scaffold pores cannot guarantee the desired cell content. Scaffolds with a sandwich structure can to some extent reduce the loss of hydrogel and cells. Cell survival has been promising in alginate 
A

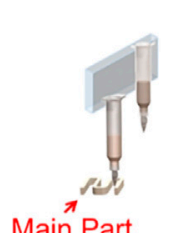

Main Part

Deposition of main and sacrificial part in first layer

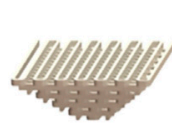

Final structure

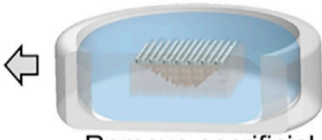

Remove sacrificial component
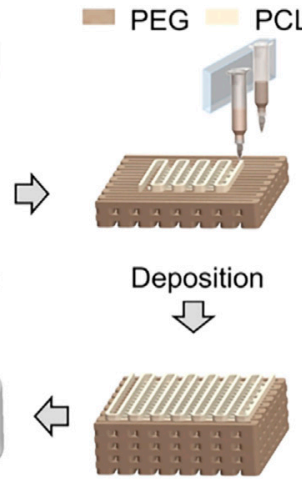

Layer-by-layer process
B

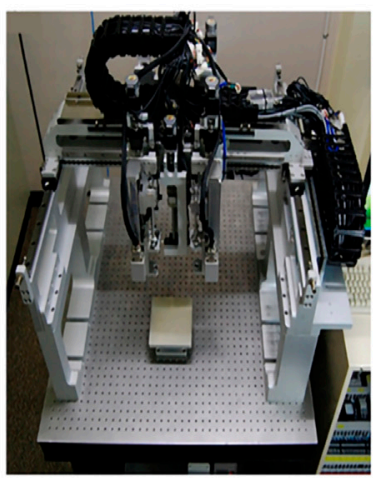

C

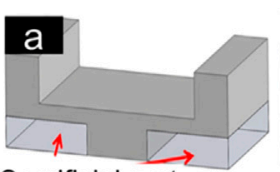

Sacrificial part

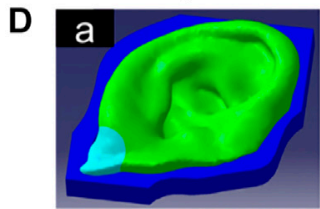

E

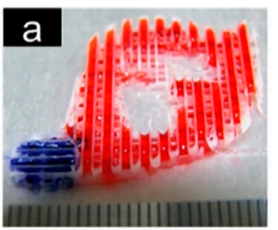

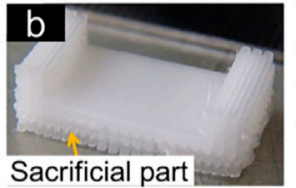
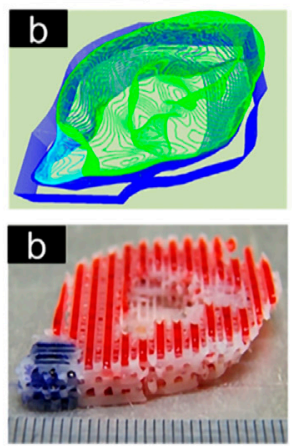

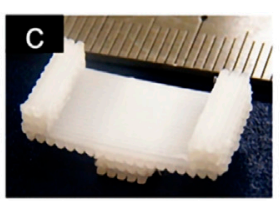

$\mathbf{F}$
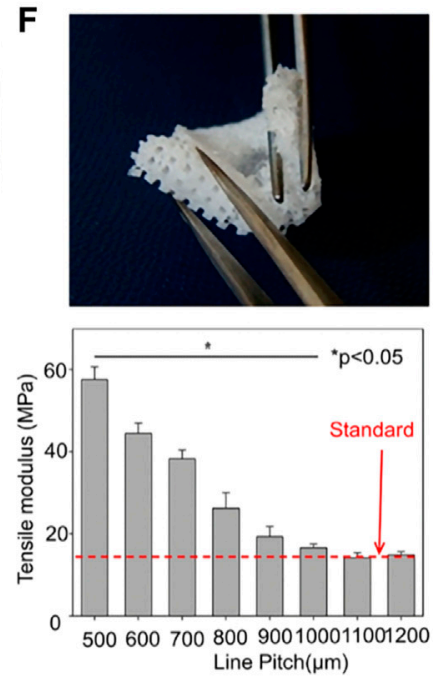

FIGURE 2 | 3D-printed auricular scaffold using sacrificial layer technology. (A) Fabrication of inverse porous pyramid structure employing sacrificial layer technology. (B) Schematic diagram of the multi-head tissue/organ building system (MtoBS). (C) Overhanging structure $(20 \mathrm{~mm} \times 10 \mathrm{~mm} \times 6 \mathrm{~mm})$. (D) The model designed by CAD software, slicing CAD model, and the Code generation to control XYZ movement of the MtoBS. (E) Scaffold after 3D printing. (F) The scaffold is flexible, and a line spacing of 1,000-1,200 $\mu \mathrm{m}$ yields a similar tensile modulus to that of the auricle (Lee et al., 2014).

TABLE 2 | Summary of 3D-printed nasal cartilage.

\begin{tabular}{|c|c|c|c|c|}
\hline Material & Seed cells & $\begin{array}{l}\text { Bioprinting } \\
\text { Technology }\end{array}$ & Key points & References \\
\hline $\begin{array}{l}\text { Gelatin methacryloyl (GelMA)/Polyethylene } \\
\text { glycol dimeth-acrylate (PEGDMA)/Gelatin }\end{array}$ & Chondrocytes & Extrusion printing & $\begin{array}{l}\text { The engineered cartilage-like tissue construct was integrated with } \\
\text { an electrochemical biosensing system to produce functional } \\
\text { olfactory sensations }\end{array}$ & $\begin{array}{l}\text { Jodat et al. } \\
(2020)\end{array}$ \\
\hline Gellan/Alginate/BioCartilage & Chondrocytes & Extrusion printing & $\begin{array}{l}\text { A novel bio-ink for printing cartilage grafts was developed for use } \\
\text { in } 3 D \text { printing }\end{array}$ & $\begin{array}{l}\text { Kesti et al. } \\
\text { (2015) }\end{array}$ \\
\hline
\end{tabular}

hydrogels placed between two printed PCL scaffolds to form a sandwich structure for auricle implantation. This new method of constructing auricular cartilage considers both mechanical properties and cell viability (Visscher et al., 2019). When selecting a hydrogel loaded with cells, adding an acellular cartilage matrix (ACM) to the gelatin can produce a hydrogel more similar to that in vivo, which is conducive to cell growth (Jia et al., 2020) (Figure 1).
Covering a PCL scaffold with PGA has been shown to be beneficial to auricular chondrocytes. The scaffold remained intact and chondrocytes differentiated into cartilage 2.5 years after implantation. This study supported the feasibility of 3Dprinted cartilage tissue for clinical applications (Zhou et al., 2018). For 3D printing, in addition to scaffold stability and cell survival in hydrogels, it is also necessary to consider the 

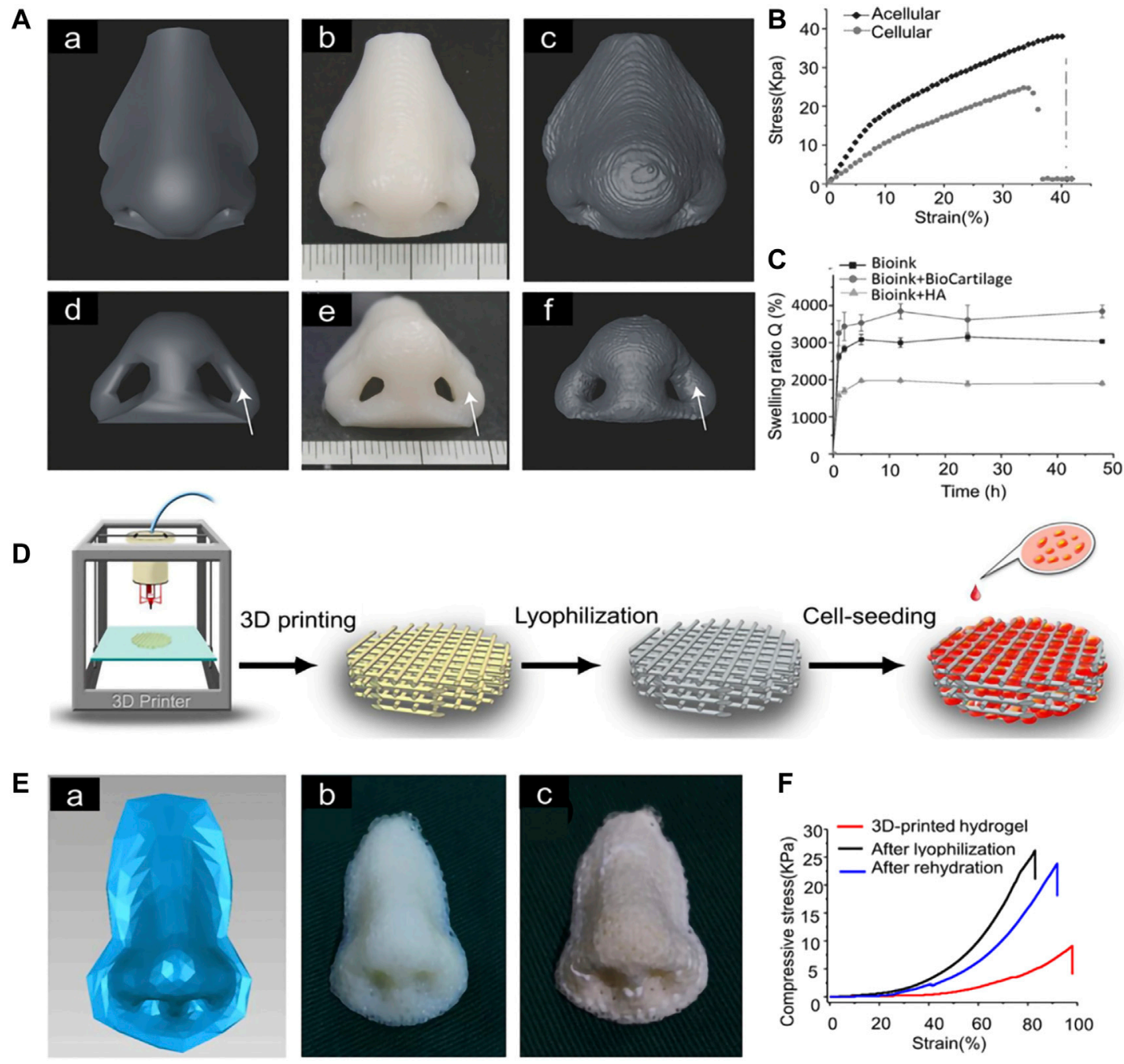

$\mathbf{F}$

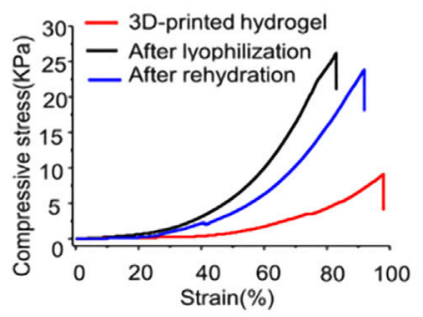

FIGURE 3 |3D-printed nasal cartilage scaffold. (A) The 3D model for printing and comparison of its shape and volume after 2 weeks of swelling (B) The Young's modulus of the acellular structure $(E=230 \pm 7.0 \mathrm{kPa}$ ) was significantly higher than that of the cellular structure $(E=116 \pm 6.8 \mathrm{kPa})$. (C) The equilibrium swelling rate of bioink + HA was significantly lower than that of bio-ink + biocartilage or bio-ink alone (Kesti et al., 2015). (D) Nasal cartilage scaffold was prepared by photocured 3D printing and lyophilization. (E) The scaffold printed according to the 3D model was lyophilized. (F) compression strength of the scaffold (Xia et al., 2018).

rheological and cross-linking properties of hydrogels. Bio-ink prepared by mixing nanofiber cellulose (NFC) with sodium alginate is promising for bio-printing because of the shearthinning effect. Moreover, the hybrid material simultaneously offers a dual-cross-linking pattern and greater storage modulus (Markstedt et al., 2015). However, further in vivo and clinical trials of hybrid materials are still required to verify their efficacy. On this basis, bacterial nano-cellulose (BNC) was modified by a water-based anti-collision agent, and the I $\beta$ phase of BNC was replaced by the I $\alpha$ phase, which was more thermodynamically stable. Higher water retention and stronger mechanical properties were obtained in this way (Apelgren et al., 2019). Studies of the feasibility of tissue engineered cartilage have been carried out in animals. As early as 1997, a group of researchers implanted PLGA-PLA structure into mice lacking a thymus, which confirmed the feasibility of auricle construction using chondrocytes and biodegradable polymers (Cao et al., 1997).

\subsubsection{D-Printed Auricular Cartilage With a Sacrificial Layer}

To make the 3D-printed scaffold more stable and complex, sacrificial layer technology was used to construct the support, with PEG as the sacrificial layer to stabilize the scaffold structure. At the same time, chondrocytes and adipocytes were implanted into corresponding positions in the scaffolds, including the cartilage and earlobe components for in vitro culture (Lee et al., 2014) (Figure 2). In recent years, in addition to commonly used materials such as PCL and PEG, the feasibility of using PU materials to print auricular cartilage has also been confirmed. Compared with the Medpor scaffold, PU has better histocompatibility and improved prospects for clinical applications. 
TABLE 3 | Summary of 3D-printed tracheal cartilage.

\begin{tabular}{|c|c|c|c|c|}
\hline Material & Seed cells & Bioprinting Technology & Key points & References \\
\hline PCL & $\begin{array}{l}\text { Human bronchial epithelial cells (hBECs)/iPSC-derived } \\
\text { mesenchymal stem cells (iPSC-MSCs)/iPSC-derived } \\
\text { chondrocytes (iPSC-Chds) }\end{array}$ & Fused deposition system & $\begin{array}{l}\text { Combined electrospinning technology and 3D } \\
\text { printing technology to print tracheal cartilage }\end{array}$ & $\begin{array}{l}\text { Kim et al. } \\
(2020)\end{array}$ \\
\hline PCL & Rabbit chondrocytes & Fused deposition system & $\begin{array}{l}\text { The 3D-printed scaffold printed with PCL was } \\
\text { loaded with cultured chondrocytes }\end{array}$ & $\begin{array}{l}\text { Gao et al. } \\
(2017)\end{array}$ \\
\hline $\mathrm{PCL}$ & Goat auricular chondrocytes & Fused deposition system & $\begin{array}{l}\text { PCL was used to print the cell scaffold, and the } \\
\text { scaffold was cellularized }\end{array}$ & Xia et al. (2019) \\
\hline PLLA & Rabbit chondrocytes & Fused deposition system & $\begin{array}{l}\text { The 3D-printed scaffolds were seeded with } \\
\text { chondrocytes obtained from autologous } \\
\text { auricles }\end{array}$ & $\begin{array}{l}\text { Gao et al. } \\
(2019)\end{array}$ \\
\hline PU & Mesenchymal stem cells (MSCs) & $\begin{array}{l}\text { Liquid-frozen deposition } \\
\text { manufacturing (LFDM) }\end{array}$ & $\begin{array}{l}\text { A tracheal scaffold printed by Pu was tested in } \\
\text { vivo }\end{array}$ & $\begin{array}{l}\text { Hsieh et al. } \\
\text { (2018) }\end{array}$ \\
\hline $\begin{array}{l}\text { PCL/ } \\
\text { Alginate }\end{array}$ & $\begin{array}{l}\text { Rabbit bone marrow-derived mesenchymal stem cells } \\
\text { (bMSC)/Epithelial Cells }\end{array}$ & & $\begin{array}{l}\text { Artificial trachea containing two cell types were } \\
\text { fabricated by three-dimensional bioprinting }\end{array}$ & $\begin{array}{l}\text { Bae et al. } \\
\text { (2018) }\end{array}$ \\
\hline
\end{tabular}

\subsection{D-Printed Nasal Cartilage}

Clinically, nasal cartilage defects have a significant impact on a person's facial appearance and olfactory function. In nasal cartilage repair, autologous cartilage or bone is often implanted into the site that needs to be repaired. The materials commonly used for nasal scaffold transplantation include bone or cartilage obtained from the nasal septum, ribs, skull, and ear (Parkhouse and Evans, 1985). However, there is a risk of graft fracture and displacement when using a graft to repair the loss of nasal cartilage (Elik and Aktan, 2019; Cao et al., 2021). Therefore, the application of 3D printing in cartilage tissue engineering can provide a rational alternative for fabrication of nasal cartilage prostheses suitable for a given individual. Many researchers are committed to combining synthetic chemical materials and natural hydrogels into scaffolds using $3 \mathrm{D}$ printing. The use of PCL and various kinds of cellular hydrogels for scaffold fabrication has attracted much research interest in recent years (Table 2).

\subsubsection{Preparation of Nasal Scaffolds With Hydrogel}

For 3D printing of nasal cartilage, researchers early on attempted to use pure hydrogel as the $3 \mathrm{D}$ printing material for nasal cartilage. However, performance of the printed nasal cartilage scaffolds can be increased by modification of the hydrogels. For example, swelling of the scaffolds can be increased significantly by adding extracellular matrix to the gel. When bio-ink for 3D printing is made of bio-cartilage, gellan gum, and alginate, the swelling rate of the scaffold is significantly greater than when it lacks bio-cartilage (Kesti et al., 2015). For scaffolds printed with hydrogel, the mechanical properties of the scaffolds can be improved by lyophilization (Xia et al., 2018) (Figure 3).

\subsubsection{Preparation of Nasal Scaffolds With Polymer Materials and Hydrogel}

In order to make the mechanical properties of 3D-printed scaffolds approximate those of natural nasal cartilage, polymer and hydrogel were selected for $3 \mathrm{D}$-printed nasal cartilage scaffolds. PCL is the most frequently used polymer. A multi-head disposition system can be applied to print PCL and alginate with both encapsulated cells and TGF- $\beta$. The cells in the printed scaffold maintained a high proliferation rate (Kundu et al., 2015). GELMA is also used to load cells and make nasal cartilage scaffolds with PCL. Moreover, $20 \% \mathrm{w} / \mathrm{v}$ gel is considered to be ideal for preparation of cartilage scaffold materials because of its rheology and improved biocompatibility (Ruiz-Cantu et al., 2020). To improve proliferation of chondrocytes on PCL scaffolds, dehydrated porcine nasal cartilage extracellular matrix was incorporated into the scaffold, which showed improved chondrogenic differentiation potential (Wiggenhauser et al., 2019). However, further research is urgently needed.

To improve nasal cartilage scaffolds, in addition to exploration of hydrogels, some have studied PCL as it mainly plays a role in maintaining shape. Filaments of carefully chosen mixtures of PCL and graphene are suitable for preparation of scaffolds by injection molding, which is conducive to growth of cartilage and can improve the mechanical properties of scaffolds (Rajzer et al., 2020). In printing cartilage scaffolds, the flexibility of the scaffold should also be considered in order to make the mechanical properties of the scaffold similar to those of nasal cartilage. Using an octahedral pore structure instead of a cube or lattice structure for 3D-printed nasal scaffolds can increase the flexibility of the scaffold and reduce the risk of prosthesis deformation and infection (Jung et al., 2014). A novel use of laser sintering to process PCL improved cell survival by controlling pore structure and promoting perfusion of the hydrogel (Zopf et al., 2015).

\subsubsection{Olfactory Restoration via a Novel Nasal Cartilage Scaffold}

In addition to focusing on aesthetics in nose reconstruction, the sense of smell should also be considered. A recent study of nasal cartilage $3 \mathrm{D}$ printing reported the addition of an olfactory sensing device, which may represent a future direction in nose reconstruction research in which function is considered along with appearance (Jodat et al., 2020). Electrospinning of gelatin fibers on the surface of $3 \mathrm{D}$ printing scaffolds can be transformed into gelatin after heating, which helps to capture cells and increase cell adhesion after inoculation. Thus they can be well distributed in the porous PLLA scaffold (Rajzer et al., 2018). 

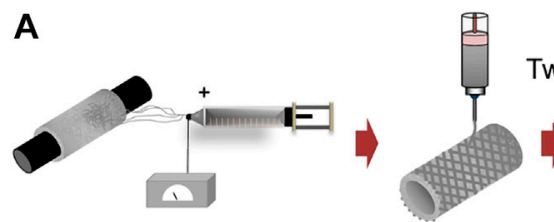

Electrospinning

C

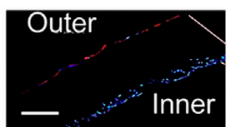

Cell seeding

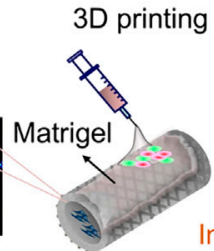

Inner layer (hBECs) and outer layer (ipsc-MSCs/Chds) embedded in Matrigel

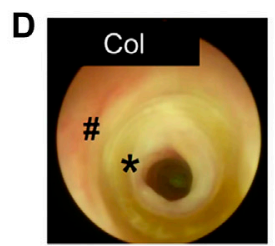

E

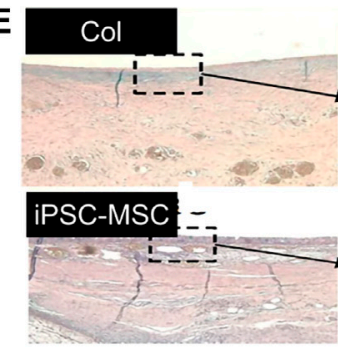

iPSC-Chd

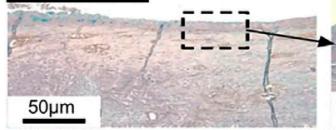

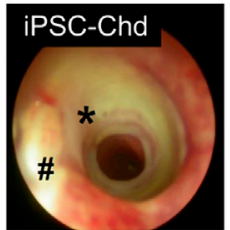

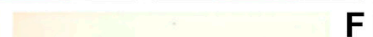

3D printed

Two-layered tubular microfiber
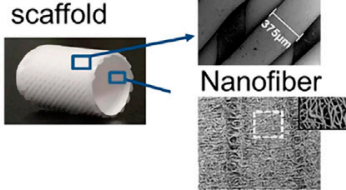

ipsc-derived MSC ipsc-derived chondrocyte hBECs

\section{B}

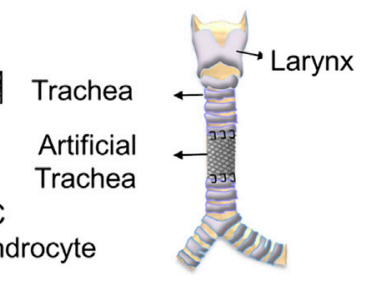

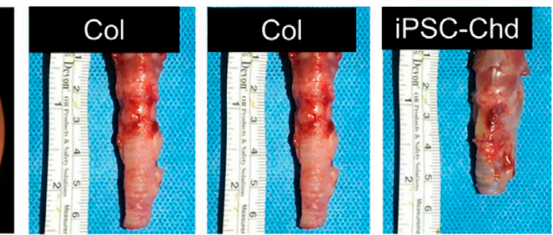

Col
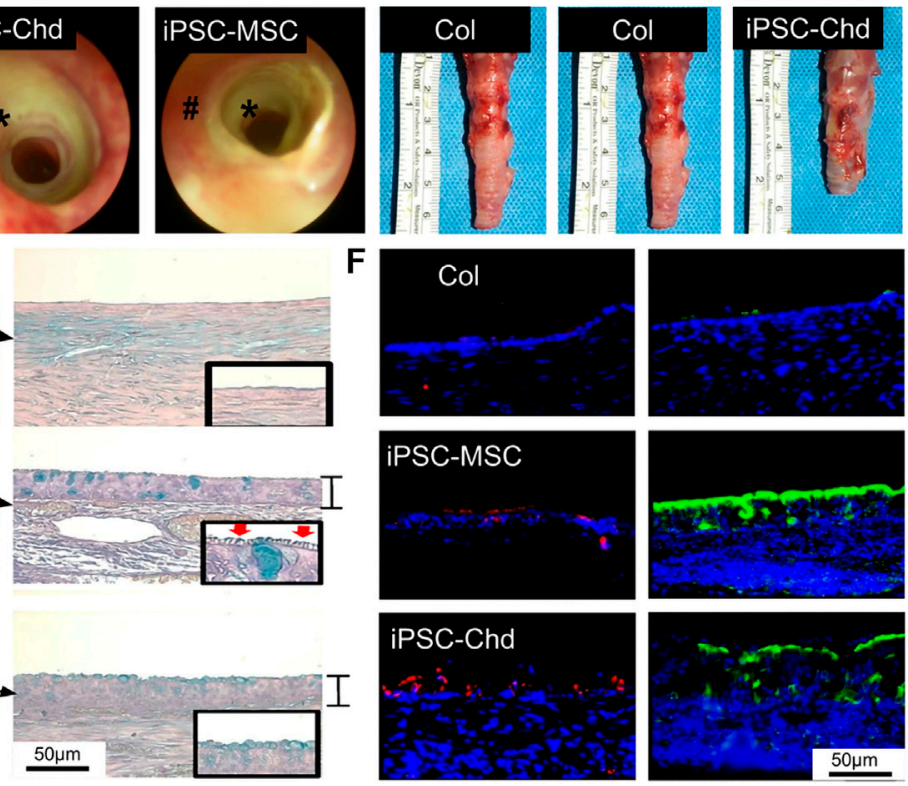

FIGURE 4 | Process diagram for manufacturing a 3D tubular artificial tracheal scaffold. (A) A PCL tubular nanofiber layer (inner layer) prepared by electrospinning was wrapped with 3D-printed PCL fiber. (B) Tracheal transplantation and endoscopic analysis. (C) Induced pluripotent stem cell-derived chondrocytes (IPSC-CHDs) and human bronchial epithelial cells (hBECs) were separately seeded on the outer and inner layers of the scaffold. Each layer was identified by pkh-26 staining (red; IPSCCHDs) and DAPI (blue; hBECs) staining (scale = $200 \mu \mathrm{m})$. (D) The endoscopic images at 4 weeks. (E) Alcian-blue staining showed mucus (blue) generated by regenerated tracheal epithelium 4 weeks after transplantation. (F) Immunofluorescence staining for $\beta$-tubulin and keratin-5 at the implant site (Kim et al., 2020).

\subsection{D-Printed Tracheal Cartilage Tissue}

Cricoid hyaline cartilage maintains tracheal shape and guides air flow into and out of the lungs. In addition, the glands in the inner layer of cartilage can release cells and granules into the body by secreting mucus (Brand-Saberi and Schäfer, 2014). There are two kinds of common tracheal diseases: tracheomalacia caused by injuries to the tracheal wall, and tracheal stenosis caused by tumors, congenital defects, and other tracheal diseases (Rich and Gullane, 2012). Severe tracheomalacia leads to tracheal stenosis and can be life threatening. Procedures for assisting breathing include noninvasive ventilation, tracheostomy, and airway stenting (Janssen et al., 2021).

Treatment of tracheal tumors depends on tumor size. If the length of a tracheal resection is greater than $6 \mathrm{~cm}$, it cannot be repaired by end-to-end anastomosis (Fabre et al., 2013); an implantable scaffold offers an alternative approach. When choosing a suitable scaffold, the mechanical strength, cell compatibility, and adhesion of the scaffold should be considered, but at present there is no perfect bionic scaffold (Jagdeep et al., 2017). In addition, for repair of tracheal injury in children, the scaffold must grow with age (Hamilton et al., 2015). Although biological 3D printing may be used to address these issues, hydrogel on its own as a scaffold material is unsuitable as it is too compliant to maintain an open channel for air flow through the trachea.

\subsubsection{Preparation of Tracheal Scaffolds Using Polymer Materials Combined With Hydrogel}

Macchiarini et al. (2009) were the first to perform trachea replacement using an acellular allogeneic annular trachea. In combination with selecting human tissue to construct trachea, emerging $3 \mathrm{D}$ printing technology can provide patients with customized tracheal prostheses. Similar to auricular and nasal cartilage scaffolds, the material used in the initial study of tracheal 

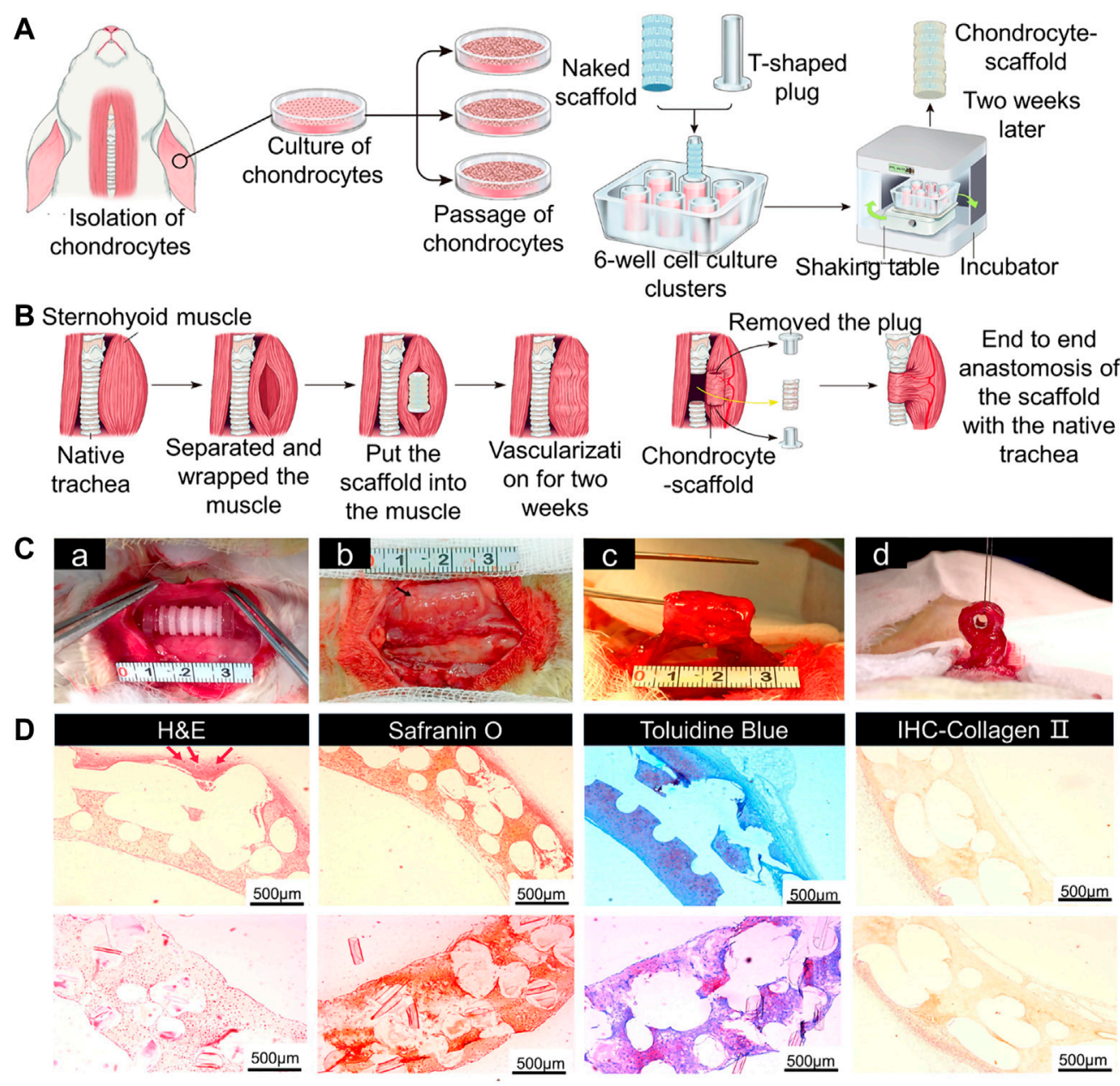

FIGURE 5 | Tracheal cartilage scaffolds were made by 3D printing technology and tested in vivo. (A) Schematic diagram of 3D-printed PLLA tracheal scaffold. (B) Pre-vascularization and tracheal reconstruction of cellular scaffold constructs in vivo. (C) The scaffold was implanted into sternal muscle for pre-vascularization. A complete segmental tracheal organ unit with pedicle muscle flap was formed. (D) The images of H\&E, safranin O, and toluidine blue staining, and IHC of type II collagen of chondrocyte-scaffold constructs. (Scale bar: $500 \mu \mathrm{m}$; red arrow: small blood vessels around the engineered trachea) (Gao et al., 2019).

printing was mostly PCL (Table 3) (She et al., 2021). An optimally structured PCL scaffold can be printed at $90^{\circ} \mathrm{C}$ with a heating nozzle (Ahn et al., 2019). Given the complexity of tracheal structure, the characteristics of each layer of a tracheal scaffold should be considered in its design. A 3D printing machine with a screw pump system and a pipe manufacturing controller has been used to print tracheal scaffolds composed of alginate combined with PCL and cells (Park et al., 2019). Porous PCL was located both inside and outside the scaffold, and the middle two layers of alginate + cells were separated by porefree PCL.

The structure of PCL scaffolds can be improved by electrospinning technology, which can improve cell viability (Yu et al., 2021). For example, PCL nanostructured scaffolds were prepared as the inner layer of a tracheal scaffold using an electrostatic spinning technique, into which human bronchial epithelial cells (HBECs) were implanted. In addition, 3D-printed PCL scaffolds have been used as the outer layer of a tracheal scaffold. Induced pluripotent stem cell-derived mesenchymal stem cells (IPSC-MSCs) and induced pluripotent stem cellderived chondrocytes (iPSC-Chds) were implanted into the outer layer of the scaffold. The outer layer of the scaffold maintained and supported the shape of the trachea. The nanostructure of the internal electrospun scaffold better simulates the extracellular matrix, which is more conducive to the growth of HBECs, enables rapid reconstruction of the mucosal layer, and can also reduce tracheal stenosis caused by incomplete reconstruction (Kim et al., 2020) (Figure 4). Comprehensive animal studies will be required before this method can be used for segmental bronchial transplantation.

The composite material obtained by adding chitosan to PCL has been used for electrospinning, which can reduce the diameter of electrospun fibers and improve the mechanical properties of the scaffold (Kim et al., 2021). To provide 3D-printed trachea with improved structure, the sacrificial layer technique has also been used in printing of tracheal cartilage. A sacrificial mold 
A

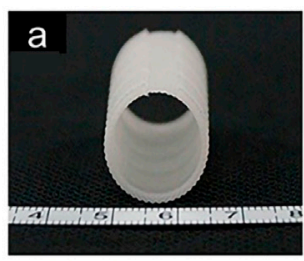

B
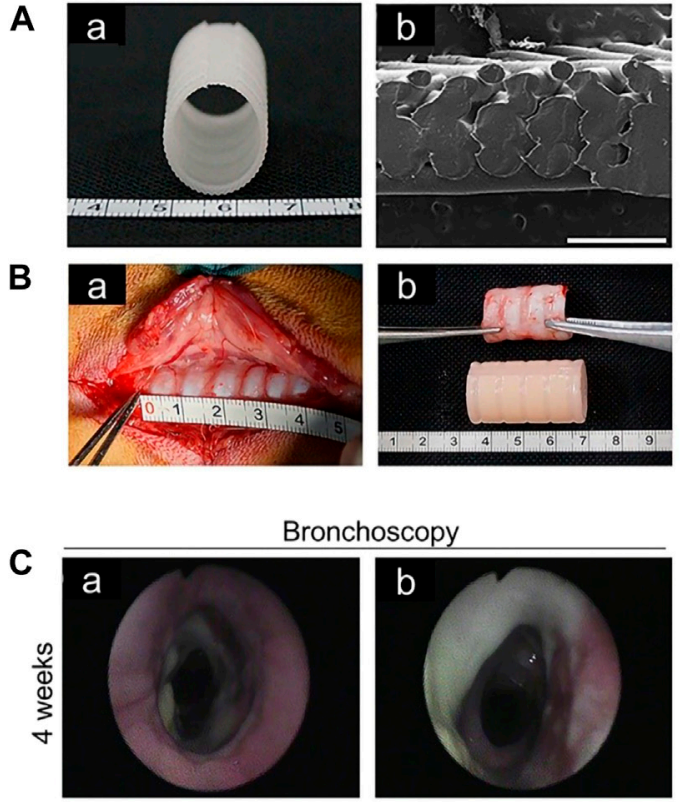

Bronchoscopy

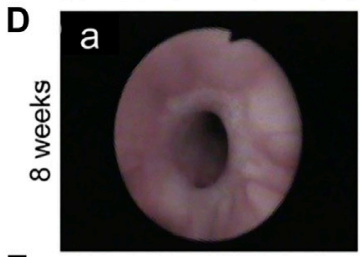

$\mathrm{E}$

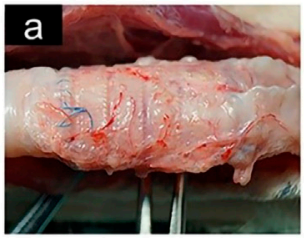

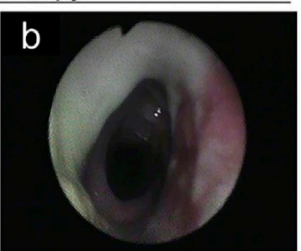

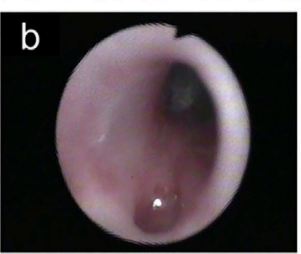

b

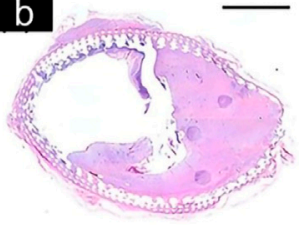

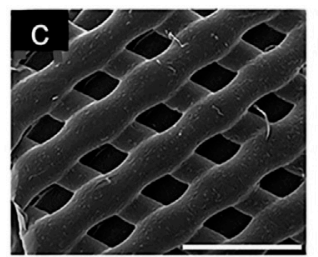
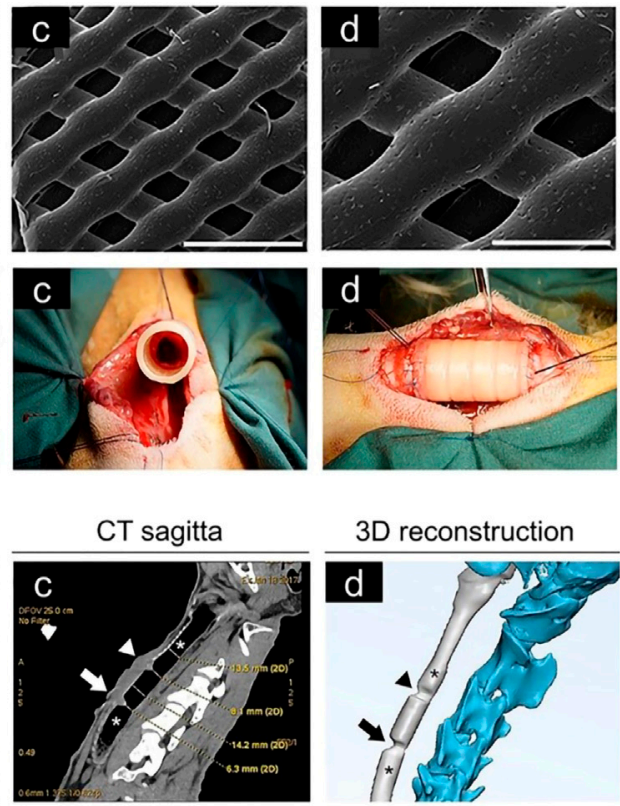

$3 \mathrm{D}$ reconstruction
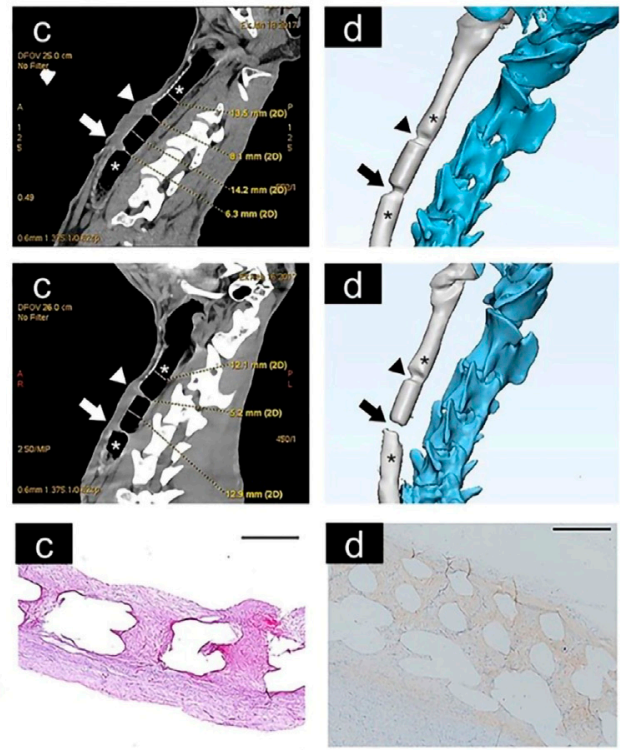

FIGURE 6 | Tracheal cartilage scaffolds were made by 3D printing technology and tested in vivo. (A) Macroscopic (a) and SEM (b-d) images of 3D-printed PCL scaffold. (B) Implantation of a tracheal cartilage scaffold. (C) Four weeks after implantation, tracheal images were acquired at the upper, middle and lower anastomosis sites, respectively $(\mathbf{a}, \mathbf{b})$. Computed tomography (CT) sagittal images and representative sections of 3D-printing reconstruction after 4 weeks, in which the narrow area represents the upper and lower anastomoses (arrow) (c,d). (D) Bronchoscopy images and CT sagittal images after 8 weeks. (E) The scaffold of the experimental group was removed at the time of death (a). Hematoxylin and eosin staining of scaffolds at low magnification (b). Representative safranin $O$ staining (c). Representative collagen II staining (d) (Xia et al., 2019).

containing hollow trachea was constructed by $3 \mathrm{D}$ printing, and then PLCL was injected into the mold to generate an annular tracheal structure. Gelatin sponges loaded with transforming growth factor- $\beta 1$ (TGF- $\beta 1$ ) and chondrocytes were placed between the annular structures to promote formation of cartilage tissue (Park et al., 2015).

In addition to commonly used PCL materials, two kinds of PU materials with different compositions were used for $3 \mathrm{D}$ printing of the hard and soft segments of tracheal wall cartilage, and the printed 3D scaffolds were then implanted into nude mice for 6 weeks. The results showed that the maximum tensile stress, Young's modulus, and elongation of the $3 \mathrm{D}$ tracheal scaffold were 4.6 $\mathrm{MPa}, 21.1 \mathrm{MPa}$, and $106.2 \%$, respectively, and the MSCs on the scaffold could be induced to differentiate into chondrocytes (Hsieh et al., 2018). TPU has elastic properties appropriate for use as a tracheal support material. Researchers printed TPU scaffolds with wave and straight pattern micro-morphology. Electrospinning was used to cover the inner and outer surfaces of the TPU scaffold to improve its biocompatibility. Electrospinning on 3D-printed tracheal scaffolds can improve cell adhesion to the scaffolds and their elastic properties (Ahn et al., 2019).

\subsubsection{Blood Supply Improvement in 3D-Printed Tracheal Scaffolds}

Blood vessels can promote growth of airway epithelium on the surface of 3D-printed scaffolds, therefore blood supply should be considered when designing tracheal cartilage scaffolds. As one approach to this problem, PLLA tracheal scaffolds were precultured with chondrocytes in vitro and pre-vascularized in vivo, 
TABLE 4 | Summary of 3D-printed meniscus cartilage.

\begin{tabular}{|c|c|c|c|c|}
\hline Material & Seed cells & Bioprinting Technology & Key points & References \\
\hline PCL & BMSCs & $\begin{array}{l}\text { Fused deposition } \\
\text { modeling (FDM) }\end{array}$ & $\begin{array}{l}\text { PCL was printed into meniscal scaffolds with } \\
\text { different pore sizes using the melt deposition } \\
\text { technique }\end{array}$ & Zhang et al. (2016) \\
\hline PCL/GelMA & Fibrochondrocytes & $\begin{array}{l}\text { Bioscaffolder system (SYS + } \\
\text { ENG, SalzgitterBad, Germany) }\end{array}$ & $\begin{array}{l}\text { Agarose and gelatin methcrylate (GelMA) hydrogels } \\
\text { were printed on the inside and outside of PCL } \\
\text { scaffold, respectively }\end{array}$ & $\begin{array}{l}\text { Bahcecioglu et al. } \\
\text { (2019) }\end{array}$ \\
\hline Gelatin/Alginate/CNF & $\begin{array}{l}\text { Rabbit } \\
\text { fibrochondrocytes (rFCs) }\end{array}$ & Extrusion printing & $\begin{array}{l}\text { The gelatin-alginate bio-ink modified with cellulose } \\
\text { nanofibers (CNF) has been verified for its feasibility } \\
\text { to print meniscus }\end{array}$ & Luo et al. (2020a) \\
\hline Silk fibroin/gelatin & $\begin{array}{l}\text { Porcine } \\
\text { fibrochondrocytes }\end{array}$ & Extrusion printing & $\begin{array}{l}\text { The scaffold made of silk fibroin and gelatin has } \\
\text { good performance after freeze-drying }\end{array}$ & $\begin{array}{l}\text { Bandyopadhyay and } \\
\text { Mandal (2019) }\end{array}$ \\
\hline $\begin{array}{l}\text { Meniscus extracellular matrix } \\
\text { (MECM)/sodium alginate }\end{array}$ & $\begin{array}{l}\text { Meniscal } \\
\text { fibrochondrocytes } \\
\text { (MFCs) }\end{array}$ & $\begin{array}{l}\text { Fused deposition } \\
\text { modeling (FDM) }\end{array}$ & $\begin{array}{l}\text { The scaffold was made of MECM-alginate bio-ink } \\
\text { and } 3 \mathrm{D} \text {-printed PCL. }\end{array}$ & Chen et al. (2019a) \\
\hline $\begin{array}{l}\text { Decellularized meniscal } \\
\text { extracellular matrix (dECM)/ } \\
\text { PU/PCL }\end{array}$ & BMSCs & FDM/Extrusion & $\begin{array}{l}\text { Hydrogel made from decellularized extracellular } \\
\text { matrix and a mixture of PCL and PU was used to } \\
\text { make meniscal scaffolds }\end{array}$ & Chae et al. (2021) \\
\hline
\end{tabular}

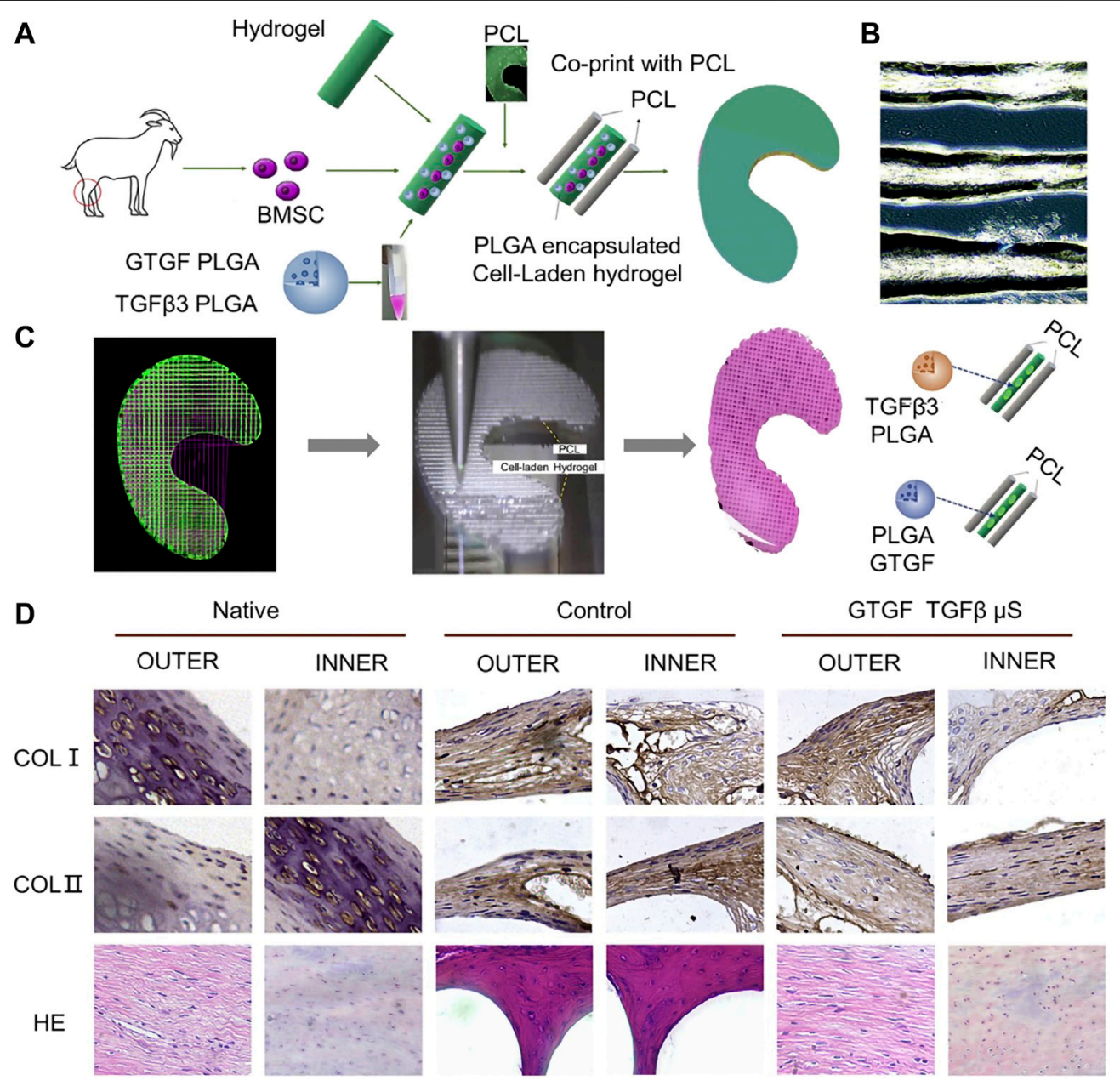

FIGURE 7 | PCL and PLGA encapsulated cell-laden hydrogel was used to make a meniscus scaffold by 3D printing technology. (A) Schematic diagram of the design of a bioprinted composite material study for regeneration of a goat meniscus. (B) PLGA-encapsulated hydrogels containing MSCs cells exhibited good printability. (C) CAD model of the meniscus for 3D printing. The cell hydrogel and PCL were printed into 3D meniscus by 3D printing technology. (D) Zone-specific matrix phenotype analysis in engineered versus native tissue (Sun et al., 2020). 
and then implanted with a muscle flap into tracheal defects in Manch rabbits (Gao et al., 2019) (Figure 5). The same group also transplanted 3D-printed trachea into sheep, which provided a basis for use of 3D-printed trachea in the clinic (Xia et al., 2019) (Figure 6).

Studies of segmental bronchial implants must also consider the problem of tracheal stenosis following transplantation. To solve this problem, some researchers use omentum to cover both ends of the prostheses to reduce complications, including luminal stenosis and mesh exposure (Teramachi et al., 1997). This method has also been used to facilitate tracheal scaffold blood flow (Masatsugu et al., 2014). In addition, by implanting a 3Dprinted PCL scaffold into an animal's omentum, it was shown that using the omentum as a $3 \mathrm{D}$-printed scaffold bioreactor can not only improve blood flow and reduce the incidence of tracheal stenosis but also promote proliferation of tracheal epithelial cells (Park et al., 2018).

\subsection{D-Printed Meniscus Cartilage Tissue}

The knee menisci are two fibrous cartilage discs in the joint that provide for shock absorption and load transmission. The lateral and medial menisci are semicircular and C-shaped, respectively (Chae et al., 2021). A meniscus can be divided into a white-white area, red-red area, and red-white area based on blood supply (Markes et al., 2020). Approximately ninety percent of meniscus injuries require meniscus removal because chondrocytes are not renewable. However, the incidence of osteoarthritis (OA) following meniscectomy is 7.4-fold higher than normal. Therefore, scaffolds with morphology and mechanical properties similar to menisci have attracted much research interest in recent years (Kwon et al., 2019; De Caro et al., 2020). For 3D printing of a tissue engineered meniscus, not only should morphological similarity be considered but also mechanical load-bearing and lubrication. A meniscus scaffold can be printed with PCL using FDM technology (Zheng-Zheng et al., 2016) (Table 4).

\subsubsection{Preparation of Meniscus Scaffolds With Hydrogel}

Among the hydrogels used in meniscus scaffolds, GelMA has superior properties for printing and can maintain higher fidelity (Daly et al., 2016). In addition, gelatin-alginate bioink containing cellulose nanofibers (CNF) has been shown to be useful for printing menisci (Luo W. et al., 2020). The mechanical properties of scaffolds made of silk fibroin and gelatin were greatly improved and made more similar to menisci by freeze-drying and cross-linking with EDC (1ethyl-3-(3-dimethylamino propyl) carbodiimide hydrochloride) and NHS (N-hydroxysuccinimide) (Bandyopadhyay and Mandal, 2019). ECM extracted from menisci mixed with cells and growth factors is promising for use in meniscus tissue engineering (Romanazzo et al., 2017). Hydrogel produced by decellularized ECM and sodium alginate can be combined with PCL to prepare meniscal scaffolds (Chen M. et al., 2019). There are differences in the properties of ECM extracted from the inner and outer menisci: inner meniscus ECM can promote chondrogenesis of fat pad-derived stem cells, while outer meniscus ECM can promote development of cells with thinner and more fibroblast-like phenotypes (Romanazzo et al., 2017).

\subsubsection{Preparation of Meniscus Scaffolds With Polymer Materials and Hydrogel}

For meniscus scaffolds made of PCL, scaffold pore size influences ECM production, cell behavior, biomechanics, and hence successful repair. A scaffold with an average pore size of $215 \mu \mathrm{m}$ not only has good tensile and compressive properties but can also promote proliferation and differentiation of MSCs (Zhang et al., 2016). A meniscus scaffold has been constructed of agarose and gelatin methacrylic acid (GelMA) hydrogels printed on both sides of a PCL scaffold. Production of glycosaminoglycans and type II collagen was promoted by agarose, while GelMA promoted production of type I collagen (Bahcecioglu et al., 2019). In addition, a scaffold made by placing silk fibroin on both sides of a 3D-printed PCL mesh also has good biocompatibility and is more suitable for tissue infiltration and blood vessel formation (Cengiz et al., 2019).

PLGA, in addition to being combined with hydrogel and ECM as a carrier of cells, can itself be loaded with cells and growth factors. For instance, PLGA microparticles loaded with MSC cells and TGF $\beta 3$ or CTGF can be deposited on a PCL scaffold to make a meniscus scaffold. Activity and proliferation of BMSCs were similar when loaded into seven types of hydrogel (Sun et al., 2020) (Figure 7). In addition to growth factors that promote cell proliferation, BMSC-specific-affinity peptide can enhance recruitment and retention of endogenous BMSCs when placed on the surface of composite scaffolds made of SF and PCL, thus reducing cell loss and enhancing scaffold chondrogenicity (Li et al., 2020). In addition to the materials discussed above, silicone can be made into a meniscus scaffold with excellent biocompatibility by using the method of heat-cured extrusion (Luis et al., 2019).

\section{FUTURE PROSPECTS}

To date there have been several technological advances in $3 \mathrm{D}$ printing of tissue-engineered cartilage, and $3 \mathrm{D}$ printing of irregularly shaped cartilage has evolved from simple morphological imitation to sophisticated biological tissue engineering. However there is still a need for in-depth research and continuous innovation to improve the effectiveness of complex tissue-engineered cartilage scaffolds.

\subsection{Optimization of Technology and Materials Required for 3D Printing}

For 3D printing of irregularly shaped cartilage scaffolds, further optimization of $3 \mathrm{D}$ printers is needed to increase the range of applications. For example, achieving more precise dynamic control of printing temperature for materials that require high or low temperature would allow for combining polymers and cellloaded hydrogels into a single scaffold. 
In terms of the choice of synthetic macromolecular polymers, the main problem to be solved is whether the hardness of the resulting material is close to that of natural cartilage. PU has been shown to have superior elastic properties, which may make it the first choice among cartilage materials in the future. For selection of cell carriers such as hydrogels, we need to identify biomaterials that can better promote cell viability. At the same time, it is hoped that some drugs, such as antibiotics or growth factors, can be mixed with hydrogels or evenly coated on 3D-printed scaffolds to reduce inflammation or promote cartilage regeneration, respectively. In addition, the material properties of synthetic macromolecular polymers and hydrogels can be modified to increase cell adhesion.

\subsection{Optimization of 3D-Printed Cartilage Scaffolds}

Research on printing of irregularly shaped 3D cartilage scaffolds has mainly focused on simulation of morphology, while only a few studies, such as those concerned with tracheal scaffolds, have considered optimization of function. For example, improving blood circulation in and around cartilage may increase biocompatibility of the overall scaffold, which may be achieved by implanting 3D-printed cartilage with embedded blood vessels into cartilage repairs. In the future, it may be possible to print auricular and nasal cartilage scaffolds and skin at the same time using 3D printing technology. For printed tracheal cartilage, materials that can adapt to airflow should be further studied. As for the meniscus, because its surface is smooth in the physiological state, this should also be true of the $3 \mathrm{D}$-printed scaffold.

\subsection{D Printing}

Based on 3D printing research, 4D printing is gradually being applied in the field of cartilage tissue engineering. The fourth dimension in $4 \mathrm{D}$ printing results from changes in conditions, e.g., light, electromagnetic fields, water, or temperature. Some materials with shape memory can restore their original shape under certain conditions (Wu et al., 2018). On this basis, the shape of the hydrogel loaded with a drug could be made to change after being implanted. This technique can not only alter the shape of the scaffold but also slow drug release. Hopefully, complex structural shapes can be optimized by $4 \mathrm{D}$ printing. In the future, it may also be possible to inject cells into the closed spaces when the $4 \mathrm{D}$-printed scaffold is deformed in order to prevent loss of cells.

\subsection{Applications In Vivo and in Clinical Trials} At present, although many kinds of research are devoted to 3D-printed cartilage scaffolds, most lack sufficient clinical trials and are not mature enough to be used in the clinic. A perfect cartilage scaffold needs in vitro and in vivo experiments

\section{REFERENCES}

Aggarwal, S., and Pittenger, M. F. (2005). Human Mesenchymal Stem Cells Modulate Allogeneic Immune Cell Responses. Blood 105 (4), 1815-1822. doi:10.1182/blood-2004-04-1559 to verify its feasibility. If it is to be used in the clinic, follow-up clinical trials are also essential. Therefore, there is still a great need for further research on 3D printing of tissue-engineered cartilage. Nevertheless, some 3D-printed scaffolds are expected to replace implant materials currently on the market.

\section{CONCLUSION}

3D-printed cartilage has been successfully utilized in various medical fields. This review discusses in detail selection and preparation of various irregularly shaped cartilage scaffolds, including auricle, nasal, tracheal, and meniscus. Using 3D printing technology, scaffolds printed with biocompatible high molecular-weight polymer materials can be combined with hydrogel and chondrocyte matrix to produce ideal irregularly shaped cartilage scaffolds. In addition, we look forward to optimization of $3 \mathrm{D}$ printing technology and the materials required for $3 \mathrm{D}$ printing. $3 \mathrm{D}$ printed cartilage scaffolds can be optimized by increasing blood supply, adding the concept of $4 \mathrm{D}$ printing, and increasing research in vivo which moves on to clinical trials. We are hopeful that these considerations will be integrated into future research.

\section{AUTHOR CONTRIBUTIONS}

HW: Writing-original draft, Funding acquisition. ZHW: Supervision. HL: Supervision. JQL: Conceptualization. RHL: Funding acquisition. XJZ: Conceptualization. MR: Conceptualization. MLW: Conceptualization. YZL: Supervision. YBL: Funding acquisition. YXJ: Funding acquisition. CYW: Investigation. JCW: Investigation and Methodology.

\section{FUNDING}

This study was supported by the National Natural Science Foundation of China (82001971, 82102358), the National Key R\&D Program of China (2018YFB1105100), the Scientific Development Program of Jilin Province (20200403088SF, 20200802008GH, 20200404202YY, 20200404140YY, 20190304123 YY, 20200404190YY, and 20190103087JH), the Program of Jilin Provincial Health Department (2020Q018, 2020SCZT064, 2020SCZT065, 2019SCZT001, 2019SCZT014, 2019SRCJ001, and 2017F007), the Youth Talents Promotion Project of Jilin Province (192004); and the Graduate Innovation Fund of Jilin University (101832020CX297).

Ahn, C. B., Son, K. H., Yu, Y. S., Kim, T. H., Lee, J. I., and Lee, J. W. (2019). Development of a Flexible 3D Printed Scaffold with a Cell-Adhesive Surface for Artificial Trachea. Biomed. Mater. 14 (5), 055001. doi:10.1088/1748-605X/ ab2a6c

Anderson, C. E. (1962). The Structure and Function of Cartilage. J. Bone Jt. Surg. 44, 777-786. doi:10.2106/00004623-196244040-00020 
Apelgren, P., Karabulut, E., Amoroso, M., Mantas, A., Martínez Ávila, H., Kölby, L., et al. (2019). In Vivo Human Cartilage Formation in Three-Dimensional Bioprinted Constructs with a Novel Bacterial Nanocellulose Bioink. ACS Biomater. Sci. Eng. 5 (5), 2482-2490. doi:10.1021/acsbiomaterials.9b00157

Bae, S. W., Lee, K. W., Park, J. H., Lee, J., Jung, C. R., Yu, J., et al. (2018). 3D Bioprinted Artificial Trachea with Epithelial Cells and ChondrogenicDifferentiated Bone Marrow-Derived Mesenchymal Stem Cells. Int. J. Mol. Sci. 19 (6), 1624. doi:10.3390/ijms19061624

Baena, J., Jiménez, G., López-Ruiz, E., Antich, C., Griñán-Lisón, C., Perán, M., et al. (2019). Volume-by-volume Bioprinting of Chondrocytes-Alginate Bioinks in High Temperature Thermoplastic Scaffolds for Cartilage Regeneration. Exp. Biol. Med. (Maywood) 244 (1), 13-21. doi:10.1177/1535370218821128

Bahcecioglu, G., Hasirci, N., Bilgen, B., and Hasirci, V. (2019). A 3D Printed PCL/ hydrogel Construct with Zone-specific Biochemical Composition Mimicking that of the Meniscus. Biofabrication 11 (2), 025002. doi:10.1088/1758-5090/ aaf707

Bandyopadhyay, A., and Mandal, B. B. (2019). A Three-Dimensional Printed SilkBased Biomimetic Tri-layered Meniscus for Potential Patient-specific Implantation. Biofabrication 12 (1), 015003. doi:10.1088/1758-5090/ab40fa

Bhattacharjee, J., Sarkar, A., and Panda, T. K. (2021). Alkali and Alkaline Earth Metal Complexes as Versatile Catalysts for Ring-Opening Polymerization of Cyclic Esters. Chem. Rec. 21 (11), 1898-1911. doi:10.1002/tcr.202100148

Brand-Saberi, B. E. M., and Schäfer, T. (2014). Trachea. Thorac. Surg. Clin. 24 (1), 1-5. doi:10.1016/j.thorsurg.2013.09.004

Cao, Y., Sang, S., An, Y., Xiang, C., Li, Y., and Zhen, Y. (2021). Progress of 3D Printing Techniques for Nasal Cartilage Regeneration. Aesth Plast. Surg. doi:10.1007/s00266-021-02472-4

Cao, Y., Vacanti, J. P., Paige, K. T., Upton, J., and Vacanti, C. A. (1997). Transplantation of Chondrocytes Utilizing a Polymer-Cell Construct to Produce Tissue-Engineered Cartilage in the Shape of a Human Ear. Plast. Reconstr. Surg. 100 (2), 297-302. discussion 303-294. doi:10.1097/00006534199708000-00001

Çelik, M., and Aktan, E. (2019). Construction of Bony-Cartilaginous Defects of the Nose. J. Craniofac. Surg. 30 (3), E234-E235. doi:10.1097/ SCS.0000000000005189

Cengiz, I. F., Pereira, H., Espregueira-Mendes, J., Kwon, I. K., Reis, R. L., and Oliveira, J. M. (2019). Suturable Regenerated Silk Fibroin Scaffold Reinforced with 3D-Printed Polycaprolactone Mesh: Biomechanical Performance and Subcutaneous Implantation. J. Mater. Sci. Mater. Med. 30 (6), 63. doi:10.1007/s10856-019-6265-3

Cenzi, R., Farina, A., Zuccarino, L., and Carinci, F. (2005). Clinical Outcome of 285 Medpor Grafts Used for Craniofacial Reconstruction. J. Craniofac. Surg. 16, 526-530. doi:10.1097/01.scs.0000168761.46700.dc

Chae, S., Lee, S.-S., Choi, Y.-J., Hong, D. H., Gao, G., Wang, J. H., et al. (2021). 3D Cell-Printing of Biocompatible and Functional Meniscus Constructs Using Meniscus-derived Bioink. Biomaterials 267, 120466. doi:10.1016/ j.biomaterials.2020.120466

Chameettachal, S., Midha, S., and Ghosh, S. (2016). Regulation of Chondrogenesis and Hypertrophy in Silk Fibroin-Gelatin-Based 3D Bioprinted Constructs. ACS Biomater. Sci. Eng. 2 (9), 1450-1463. doi:10.1021/acsbiomaterials.6b00152

Chen, M., Feng, Z., Guo, W., Yang, D., Gao, S., Li, Y., et al. (2019). PCL-MECMBased Hydrogel Hybrid Scaffolds and Meniscal Fibrochondrocytes Promote Whole Meniscus Regeneration in a Rabbit Meniscectomy Model. ACS Appl. Mater. Inter. 11 (44), 41626-41639. doi:10.1021/acsami.9b13611

Chen, X., Chen, G., Wang, G., Zhu, P., and Gao, C. (2019). Recent Progress on 3DPrinted Polylactic Acid and its Applications in Bone Repair. Adv. Eng. Mater. 22 (4), 1901065. doi:10.1002/adem.201901065

Cheng, L., Yao, B., Hu, T., Cui, X., Shu, X., Tang, S., et al. (2019). Properties of an Alginate-Gelatin-Based Bioink and its Potential Impact on Cell Migration, Proliferation, and Differentiation. Int. J. Biol. Macromolecules 135, 1107-1113. doi:10.1016/j.ijbiomac.2019.06.017

Cheng, Y.-L., and Chen, F. (2017). Preparation and Characterization of Photocured Poly ( $\varepsilon$-Caprolactone) Diacrylate/poly (Ethylene Glycol) Diacrylate/chitosan for Photopolymerization-type 3D Printing Tissue Engineering Scaffold Application. Mater. Sci. Eng. C 81, 66-73. doi:10.1016/j.msec.2017.07.025

Chia, H. N., and Wu, B. M. (2015). Recent Advances in 3D Printing of Biomaterials. J. Biol. Eng. 9, 4. doi:10.1186/s13036-015-0001-4
Chung, J. H. Y., Kade, J. C., Jeiranikhameneh, A., Ruberu, K., Mukherjee, P., Yue, Z., et al. (2020). 3D Hybrid Printing Platform for Auricular Cartilage Reconstruction. Biomed. Phys. Eng. Express 6 (3), 035003. doi:10.1088/20571976/ab54a7

Contentin, R., Demoor, M., Concari, M., Desancé, M., Audigié, F., Branly, T., et al. (2019). Comparison of the Chondrogenic Potential of Mesenchymal Stem Cells Derived from Bone Marrow and Umbilical Cord Blood Intended for Cartilage Tissue Engineering. Stem Cel Rev Rep 16 (1), 126-143. doi:10.1007/s12015-01909914-2

Daly, A. C., Critchley, S. E., Rencsok, E. M., and Kelly, D. J. (2016). A Comparison of Different Bioinks for 3D Bioprinting of Fibrocartilage and Hyaline Cartilage. Biofabrication 8 (4), 045002. doi:10.1088/1758-5090/8/4/045002

De Caro, F., Perdisa, F., Dhollander, A., Verdonk, R., and Verdonk, P. (2020). Meniscus Scaffolds for Partial Meniscus Defects. Clin. Sports Med. 39 (1), 83-92. doi:10.1016/j.csm.2019.08.011

Ding, J., Chen, B., Lv, T., Liu, X., Fu, X., Wang, Q., et al. (2016). Bone Marrow Mesenchymal Stem Cell-Based Engineered Cartilage Ameliorates Polyglycolic Acid/Polylactic Acid Scaffold-Induced Inflammation through M2 Polarization of Macrophages in a Pig Model. STEM CELLS Translational Med. 5 (8), 1079-1089. doi:10.5966/sctm.2015-0263

Dong, L., Wang, S.-J., Zhao, X.-R., Zhu, Y.-F., and Yu, J.-K. (2017). 3D- Printed Poly( $\varepsilon$-Caprolactone) Scaffold Integrated with Cell-Laden Chitosan Hydrogels for Bone Tissue Engineering. Sci. Rep. 7 (1), 13412. doi:10.1038/s41598-01713838-7

Dranseikiene, D., Schrüfer, S., Schubert, D. W., Reakasame, S., and Boccaccini, A. R. (2020). Cell-laden Alginate Dialdehyde-Gelatin Hydrogels Formed in 3D Printed Sacrificial Gel. J. Mater. Sci. Mater. Med. 31 (3), 31. doi:10.1007/s10856020-06369-7

Duan, B., Hockaday, L. A., Kang, K. H., and Butcher, J. T. (2013). 3D Bioprinting of Heterogeneous Aortic Valve Conduits with Alginate/gelatin Hydrogels. J. Biomed. Mater. Res. 101A (5), 1255-1264. doi:10.1002/jbm.a.34420

Dutta, S. D., Hexiu, J., Patel, D. K., Ganguly, K., and Lim, K.-T. (2021). 3D-printed Bioactive and Biodegradable Hydrogel Scaffolds of Alginate/gelatin/cellulose Nanocrystals for Tissue Engineering. Int. J. Biol. Macromolecules 167, 644-658. doi:10.1016/j.ijbiomac.2020.12.011

Fabre, D., Kolb, F., Fadel, E., Mercier, O., Mussot, S., Le Chevalier, T., et al. (2013). Successful Tracheal Replacement in Humans Using Autologous Tissues: An 8Year Experience. Ann. Thorac. Surg. 96 (4), 1146-1155. doi:10.1016/ j.athoracsur.2013.05.073

Farzan, A., Borandeh, S., Zanjanizadeh Ezazi, N., Lipponen, S., Santos, H. A., and Seppälä, J. (2020). 3D Scaffolding of Fast Photocurable Polyurethane for Soft Tissue Engineering by Stereolithography: Influence of Materials and Geometry on Growth of Fibroblast Cells. Eur. Polym. J. 139, 109988. doi:10.1016/ j.eurpolymj.2020.109988

Fenton, O. S., Paolini, M., Andresen, J. L., Müller, F. J., and Langer, R. (2020). Outlooks on Three-Dimensional Printing for Ocular Biomaterials Research. J. Ocul. Pharmacol. Ther. 36 (1), 7-17. doi:10.1089/jop.2018.0142

Foerster, D. W. (1966a). Total Reconstruction of the External Ear. J. Okla. State. Med. Assoc. 59 (11), 606-608.

Francis, S. L., Di Bella, C., Wallace, G. G., and Choong, P. F. M. (2018a). Cartilage Tissue Engineering Using Stem Cells and Bioprinting Technology-Barriers to Clinical Translation. Front. Surg. 5, 70. doi:10.3389/fsurg.2018.00070

Francis, S. L., Duchi, S., Onofrillo, C., Di Bella, C., and Choong, P. F. M. (2018b). Adipose-Derived Mesenchymal Stem Cells in the Use of Cartilage Tissue Engineering: The Need for a Rapid Isolation Procedure. Stem Cell Int. 2018, 1-9. doi:10.1155/2018/8947548

Gao, B., Jing, H., Gao, M., Wang, S., Fu, W., Zhang, X., et al. (2019). Longsegmental Tracheal Reconstruction in Rabbits with Pedicled Tissue-Engineered Trachea Based on a 3D-Printed Scaffold. Acta Biomater. 97, 177-186. doi:10.1016/j.actbio.2019.07.043

Gentile, P., Chiono, V., Carmagnola, I., and Hatton, P. (2014). An Overview of Poly(lactic-Co-Glycolic) Acid (PLGA)-Based Biomaterials for Bone Tissue Engineering. Ijms 15 (3), 3640-3659. doi:10.3390/ijms 15033640

Gradwohl, M., Chai, F., Payen, J., Guerreschi, P., Marchetti, P., and Blanchemain, N. (2021). Effects of Two Melt Extrusion Based Additive Manufacturing Technologies and Common Sterilization Methods on the Properties of a Medical Grade PLGA Copolymer. Polymers 13 (4), 572. doi:10.3390/ polym 13040572 
Griffin, M., Castro, N., Bas, O., Saifzadeh, S., Butler, P., and Hutmacher, D. W. (2020). The Current Versatility of Polyurethane Three-Dimensional Printing for Biomedical Applications. Tissue Eng. B: Rev. 26 (3), 272-283. doi:10.1089/ ten.TEB.2019.0224

Gu, B. K., Choi, D. J., Park, S. J., Kim, M. S., Kang, C. M., and Kim, C.-H. (2016). 3dimensional Bioprinting for Tissue Engineering Applications. Biomater. Res. 20 (1), 12. doi:10.1186/s40824-016-0058-2

Guo, T., Holzberg, T. R., Lim, C. G., Gao, F., Gargava, A., Trachtenberg, J. E., et al. (2017). 3D Printing PLGA: a Quantitative Examination of the Effects of Polymer Composition and Printing Parameters on Print Resolution. Biofabrication 9 (2), 024101. doi:10.1088/1758-5090/aa6370

Hamaji, M., Kojima, F., Koyasu, S., Tsuruyama, T., Komatsu, T., Ikuno, T., et al. (2014). Development of a Composite and Vascularized Tracheal Scaffold in the Omentum for In Situ Tissue Engineering: a Canine Model. Interactive CardioVascular Thorac. Surg. 19 (3), 357-362. doi:10.1093/icvts/ivu177

Hamilton, N. J., Kanani, M., Roebuck, D. J., Hewitt, R. J., Cetto, R., CulmeSeymour, E. J., et al. (2015). Tissue-Engineered Tracheal Replacement in a Child: A 4-Year Follow-Up Study. Am. J. Transplant. 15 (10), 2750-2757. doi:10.1111/ajt.13318

Honkanen, J. T. J., Turunen, M. J., Tiitu, V., Jurvelin, J. S., and Töyräs, J. (2016). Transport of Iodine Is Different in Cartilage and Meniscus. Ann. Biomed. Eng. 44 (7), 2114-2122. doi:10.1007/s10439-015-1513-2

Hsieh, C.-T., Liao, C.-Y., Dai, N.-T., Tseng, C.-S., Yen, B. L., and Hsu, S.-h. (2018). 3D Printing of Tubular Scaffolds with Elasticity and Complex Structure from Multiple Waterborne Polyurethanes for Tracheal Tissue Engineering. Appl. Mater. Today 12, 330-341. doi:10.1016/j.apmt.2018.06.004

Hsieh, F.-Y., and Hsu, S.-h. (2015). 3D Bioprinting: A New Insight into the Therapeutic Strategy of Neural Tissue Regeneration. Organogenesis 11 (4), 153-158. doi:10.1080/15476278.2015.1123360

Hull, C. W. (1996). Apparatus for Production of Three-Dimensional Objects by Stereolithography. US5556590 A.

Jang, C. H., Koo, Y., and Kim, G. (2020). ASC/chondrocyte-laden Alginate Hydrogel/PCL Hybrid Scaffold Fabricated Using 3D Printing for Auricle Regeneration. Carbohydr. Polym. 248, 116776. doi:10.1016/ j.carbpol.2020.116776

Jang, Y., Koh, Y. G., Choi, Y.-J., Kim, S.-H., Yoon, D. S., Lee, M., et al. (2015). Characterization of Adipose Tissue-Derived Stromal Vascular Fraction for Clinical Application to Cartilage Regeneration. In Vitro Cell.Dev.Biol.-Animal 51 (2), 142-150. doi:10.1007/s11626-014-9814-6

Janssen, A., Mastouri, M., Boboli, H., Demarche, M., Brandt, H., Moonen, V., et al. (2021). Treatment of Tracheo(broncho)malacia in Children. Rev. Med. Liege 76 (3), 145-151.

Jia, L., Zhang, Y., Yao, L., Zhang, P., Ci, Z., Zhang, W., et al. (2020). Regeneration of Human-Ear-Shaped Cartilage with Acellular Cartilage Matrix-Based Biomimetic Scaffolds. Appl. Mater. Today 20, 100639. doi:10.1016/ j.apmt.2020.100639

Jo, C. H., Lee, Y. G., Shin, W. H., Kim, H., Chai, J. W., Jeong, E. C., et al. (2014). Intra-Articular Injection of Mesenchymal Stem Cells for the Treatment of Osteoarthritis of the Knee: A Proof-of-Concept Clinical Trial. Stem Cells 32 (5), 1254-1266. doi:10.1002/stem.1634

Jodat, Y. A., Kiaee, K., Vela Jarquin, D., De la Garza Hernández, R. L., Wang, T., Joshi, S., et al. (2020). A 3D-Printed Hybrid Nasal Cartilage with Functional Electronic Olfaction. Adv. Sci. 7 (5), 1901878. doi:10.1002/ advs.201901878

Jung, C. S., Kim, B. K., Lee, J., Min, B.-H., and Park, S.-H. (2018). Development of Printable Natural Cartilage Matrix Bioink for 3D Printing of Irregular Tissue Shape. Tissue Eng. Regen. Med. 15 (2), 155-162. doi:10.1007/s13770-0170104-8

Jung, J. W., Park, J. H., Hong, J. M., Kang, H.-W., and Cho, D.-W. (2014). Octahedron Pore Architecture to Enhance Flexibility of Nasal Implant-Shaped Scaffold for Rhinoplasty. Int. J. Precis. Eng. Manuf. 15 (12), 2611-2616. doi:10.1007/s12541-014-0634-0

Jung, B. K., Kim, J. Y., Kim, Y. S., Roh, T. S., Seo, A., Park, K. H., et al. (2019). Ideal Scaffold Design for Total Ear Reconstruction Using a Three-Dimensional Printing Technique. J. Biomed. Mater. Res. Part B Appl. Biomater. 107 (4), 1295-1303. doi:10.1002/jbm.b.34222
Kačarević, Ž., Rider, P., Alkildani, S., Retnasingh, S., Smeets, R., Jung, O., et al. (2018). An Introduction to 3D Bioprinting: Possibilities, Challenges and Future Aspects. Materials 11 (11), 2199. doi:10.3390/ma11112199

Kang, H.-W., Lee, S. J., Ko, I. K., Kengla, C., Yoo, J. J., and Atala, A. (2016). A 3D Bioprinting System to Produce Human-Scale Tissue Constructs with Structural Integrity. Nat. Biotechnol. 34 (3), 312-319. doi:10.1038/nbt.3413

Kesti, M., Eberhardt, C., Pagliccia, G., Kenkel, D., Grande, D., Boss, A., et al. (2015). Bioprinting Complex Cartilaginous Structures with Clinically Compliant Biomaterials. Adv. Funct. Mater. 25 (48), 7406-7417. doi:10.1002/ adfm. 201503423

Khoshnood, N., Zamanian, A., and Abbasi, M. (2021). The Potential Impact of Polyethylenimine on Biological Behavior of 3D-Printed Alginate Scaffolds. Int. J. Biol. Macromolecules 178 (4), 19-28. doi:10.1016/j.ijbiomac.2021.02.152

Kim, B. S., Jang, J., Chae, S., Gao, G., Kong, J.-S., Ahn, M., et al. (2016). Threedimensional Bioprinting of Cell-Laden Constructs with Polycaprolactone Protective Layers for Using Various Thermoplastic Polymers. Biofabrication 8 (3), 035013. doi:10.1088/1758-5090/8/3/035013

Kim, H., Lee, J. Y., Han, H., Cho, W.-W., Han, H., Choi, A., et al. (2021). Improved Chondrogenic Performance with Protective Tracheal Design of Chitosan Membrane Surrounding 3D-Printed Trachea. Sci. Rep. 11 (1), 9258. doi:10.1038/s41598-021-88830-3

Kim, I. G., Park, S. A., Lee, S.-H., Choi, J. S., Cho, H., Lee, S. J., et al. (2020). Transplantation of a 3D-Printed Tracheal Graft Combined with iPS CellDerived MSCs and Chondrocytes. Sci. Rep. 10 (1), 4326. doi:10.1038/s41598020-61405-4

Kim, H. Y., Jung, S. Y., Lee, S. J., Lee, H. J., Truong, M.-D., and Kim, H. S. (2019). Fabrication and Characterization of 3D-Printed Elastic Auricular Scaffolds: A Pilot Study. The Laryngoscope 129 (2), 351-357. doi:10.1002/lary.27344

Kim, M. H., Lee, Y. W., Jung, W.-K., Oh, J., and Nam, S. Y. (2019). Enhanced Rheological Behaviors of Alginate Hydrogels with Carrageenan for ExtrusionBased Bioprinting. J. Mech. Behav. Biomed. Mater. 98, 187-194. doi:10.1016/ j.jmbbm.2019.06.014

Kong, H. J., Kaigler, D., Kim, K., and Mooney, D. J. (2004). Controlling Rigidity and Degradation of Alginate Hydrogels via Molecular Weight Distribution. Biomacromolecules 5 (5), 1720-1727. doi:10.1021/bm049879r

Kundu, J., Shim, J.-H., Jang, J., Kim, S.-W., and Cho, D.-W. (2015). An Additive Manufacturing-Based PCL-Alginate-Chondrocyte Bioprinted Scaffold for Cartilage Tissue Engineering. J. Tissue Eng. Regen. Med. 9 (11), 1286-1297. doi:10.1002/term.1682

Kwon, H., Brown, W. E., Lee, C. A., Wang, D., Paschos, N., Hu, J. C., et al. (2019). Surgical and Tissue Engineering Strategies for Articular Cartilage and Meniscus Repair. Nat. Rev. Rheumatol. 15 (9), 550-570. doi:10.1038/s41584-019-0255-1

Le, H., Xu, W., Zhuang, X., Chang, F., Wang, Y., and Ding, J. (2020). Mesenchymal Stem Cells for Cartilage Regeneration. J. Tissue Eng. 11, 204173142094383. doi:10.1177/2041731420943839

Lee, J.-S., Hong, J. M., Jung, J. W., Shim, J.-H., Oh, J.-H., and Cho, D.-W. (2014). 3D Printing of Composite Tissue with Complex Shape Applied to Ear Regeneration. Biofabrication 6 (2), 024103. doi:10.1088/1758-5082/6/2/024103

Li, H., Liao, Z., Yang, Z., Gao, C., Fu, L., Li, P., et al. (2021). 3D Printed Poly( $\varepsilon-$ Caprolactone)/Meniscus Extracellular Matrix Composite Scaffold Functionalized with Kartogenin-Releasing PLGA Microspheres for Meniscus Tissue Engineering. Front. Bioeng. Biotechnol. 9, 662381. doi:10.3389/ fbioe.2021.662381

Li, X., Wang, M., Jing, X., Guo, W., Hao, C., Zhang, Y., et al. (2018). Bone Marrowand Adipose Tissue-Derived Mesenchymal Stem Cells: Characterization, Differentiation, and Applications in Cartilage Tissue Engineering. Crit. Rev. Eukaryot. Gene Expr. 28 (4), 285-310. doi:10.1615/ CritRevEukaryotGeneExpr.2018023572

Li, Z., Wu, N., Cheng, J., Sun, M., Yang, P., Zhao, F., et al. (2020). Biomechanically, Structurally and Functionally Meticulously Tailored Polycaprolactone/silk Fibroin Scaffold for Meniscus Regeneration. Theranostics 10 (11), 5090-5106. doi:10.7150/thno.44270

Liu, P., Shen, H., Zhi, Y., Si, J., Shi, J., Guo, L., et al. (2019). 3D Bioprinting and In Vitro Study of Bilayered Membranous Construct with Human Cells-Laden Alginate/gelatin Composite Hydrogels. Colloids Surf. B: Biointerfaces 181, 1026-1034. doi:10.1016/j.colsurfb.2019.06.069 
Liu, Q., Li, Q., Xu, S., Zheng, Q., and Cao, X. (2018). Preparation and Properties of 3D Printed Alginate-Chitosan Polyion Complex Hydrogels for Tissue Engineering. Polymers 10 (6), 664. doi:10.3390/polym10060664

Liu, F., Liu, C., Zheng, B., He, J., Liu, J., Chen, C., et al. (2020). Synergistic Effects on Incorporation of $\beta$-Tricalcium Phosphate and Graphene Oxide Nanoparticles to Silk Fibroin/Soy Protein Isolate Scaffolds for Bone Tissue Engineering. Polymers 12 (1), 69. doi:10.3390/polym12010069

Liu, W., Feng, Z., Ou-Yang, W., Pan, X., Wang, X., Huang, P., et al. (2020). 3D Printing of Implantable Elastic PLCL Copolymer Scaffolds. Soft Matter 16 (8), 2141-2148. doi:10.1039/c9sm02396h

Lo, W.-C., Chen, W.-H., Lin, T.-C., Hwang, S.-M., Zeng, R., Hsu, W.-C., et al. (2013). Preferential Therapy for Osteoarthritis by Cord Blood MSCs through Regulation of Chondrogenic Cytokines. Biomaterials 34 (20), 4739-4748. doi:10.1016/j.biomaterials.2013.03.016

Long, J., Etxeberria, A. E., Nand, A. V., Bunt, C. R., Ray, S., and Seyfoddin, A. (2019). A 3D Printed Chitosan-Pectin Hydrogel Wound Dressing for Lidocaine Hydrochloride Delivery. Mater. Sci. Eng. C 104, 109873. doi:10.1016/ j.msec.2019.109873

Luis, E., Pan, H. M., Sing, S. L., Bastola, A. K., Goh, G. D., Goh, G. L., et al. (2019). Silicone 3D Printing: Process Optimization, Product Biocompatibility, and Reliability of Silicone Meniscus Implants. 3D Printing and Additive Manufacturing 6 (6), 319-332. doi:10.1089/3dp.2018.0226

Luo, K., Wang, L., Chen, X., Zeng, X., Zhou, S., Zhang, P., et al. (2020a). Biomimetic Polyurethane 3D Scaffolds Based on Polytetrahydrofuran Glycol and Polyethylene Glycol for Soft Tissue Engineering. Polymers 12 (11), 2631. doi:10.3390/polym 12112631

Luo, W., Song, Z., Wang, Z., Wang, Z., Li, Z., Wang, C., et al. (2020b). Printability Optimization of Gelatin-Alginate Bioinks by Cellulose Nanofiber Modification for Potential Meniscus Bioprinting. J. Nanomater. 2020, 1-13. doi:10.1155/ 2020/3863428

Luo, Y., Wei, X., Wan, Y., Lin, X., Wang, Z., and Huang, P. (2019). 3D Printing of Hydrogel Scaffolds for Future Application in Photothermal Therapy of Breast Cancer and Tissue Repair. Acta Biomater. 92, 37-47. doi:10.1016/ j.actbio.2019.05.039

Macchiarini, P., Jungebluth, P., Go, T., Asnaghi, M. A., Rees, L. E., Cogan, T. A., et al. (2009). Clinical Transplantation of a Tissue-Engineered Airway. Lancet 372 (9655), 2023-2030. doi:10.1016/S0140-6736(08)61598-6

Markes, A. R., Hodax, J. D., and Ma, C. B. (2020). Meniscus Form and Function. Clin. Sports Med. 39 (1), 1-12. doi:10.1016/j.csm.2019.08.007

Markstedt, K., Mantas, A., Tournier, I., Martínez Ávila, H., Hägg, D., and Gatenholm, P. (2015). 3D Bioprinting Human Chondrocytes with Nanocellulose-Alginate Bioink for Cartilage Tissue Engineering Applications. Biomacromolecules 16 (5), 1489-1496. doi:10.1021/ acs.biomac.5b00188

Masutani, K., and Kimura, Y. (2017). "Present Situation and Future Perspectives of Poly(lactic Acid)," in Synthesis, Structure and Properties of Poly(lactic Acid), 279, 1-25. doi:10.1007/12_2016_16

Melo, B. A. G., Jodat, Y. A., Mehrotra, S., Calabrese, M. A., Kamperman, T., Mandal, B. B., et al. (2019). 3D Printed Cartilage-Like Tissue Constructs with Spatially Controlled Mechanical Properties. Adv. Funct. Mater. 29 (51), 1906330. doi:10.1002/adfm.201906330

Merceron, T. K., Burt, M., Seol, Y.-J., Kang, H.-W., Lee, S. J., Yoo, J. J., et al. (2015). A 3D Bioprinted Complex Structure for Engineering the MuscleTendon Unit. Biofabrication 7 (3), 035003. doi:10.1088/1758-5090/7/3/ 035003

Morrison, R. J., Nasser, H. B., Kashlan, K. N., Zopf, D. A., Milner, D. J., Flanangan, C. L., et al. (2018). Co-culture of Adipose-Derived Stem Cells and Chondrocytes on Three-Dimensionally Printed Bioscaffolds for Craniofacial Cartilage Engineering. The Laryngoscope 128 (7), E251-E257. doi:10.1002/lary.27200

Mouser, V. H. M., Levato, R., Bonassar, L. J., D’Lima, D. D., Grande, D. A., Klein, T. J., et al. (2017). Three-Dimensional Bioprinting and its Potential in the Field of Articular Cartilage Regeneration. Cartilage 8 (4), 327-340. doi:10.1177/ 1947603516665445

Mouser, V. H. M., Levato, R., Mensinga, A., Dhert, W. J. A., Gawlitta, D., and Malda, J. (2020). Bio-ink Development for Three-Dimensional Bioprinting of Hetero-Cellular Cartilage Constructs. Connect. Tissue Res. 61 (2), 137-151. doi:10.1080/03008207.2018.1553960
Mu, X., Fitzpatrick, V., and Kaplan, D. L. (2020). From Silk Spinning to 3D Printing: Polymer Manufacturing Using Directed Hierarchical Molecular Assembly. Adv. Healthc. Mater. 9 (15), 1901552. doi:10.1002/ adhm.201901552

Neubauer, V. J., Döbl, A., and Scheibel, T. (2021). Silk-Based Materials for Hard Tissue Engineering. Materials 14 (3), 674. doi:10.3390/ma14030674

Neubauer, V. J., and Scheibel, T. (2020). Spider Silk Fusion Proteins for Controlled Collagen Binding and Biomineralization. ACS Biomater. Sci. Eng. 6 (10), 5599-5608. doi:10.1021/acsbiomaterials.0c00818

Ni, T., Liu, M., Zhang, Y., Cao, Y., and Pei, R. (2020). 3D Bioprinting of Bone Marrow Mesenchymal Stem Cell-Laden Silk Fibroin Double Network Scaffolds for Cartilage Tissue Repair. Bioconjug. Chem. 31 (8), 1938-1947. doi:10.1021/ acs.bioconjchem.0c00298

Olubamiji, A. D., Izadifar, Z., Si, J. L., Cooper, D. M. L., Eames, B. F., and Chen, D. X. (2016). Modulating Mechanical Behaviour of 3D-Printed Cartilage-Mimetic PCL Scaffolds: Influence of Molecular Weight and Pore Geometry. Biofabrication 8 (2), 025020. doi:10.1088/1758-5090/8/2/025020

Oveissi, F., Tavakoli, N., Minaiyan, M., Mofid, M. R., and Taheri, A. (2020). Alginate Hydrogel Enriched with Ambystoma mexicanum Epidermal Lipoxygenase-Loaded Pectin Nanoparticles for Enhanced Wound Healing. J. Biomater. Appl. 34 (8), 1171-1187. doi:10.1177/0885328219896704

Park, H. S., Lee, J. S., Jung, H., Kim, D. Y., Kim, S. W., Sultan, M. T., et al. (2018). An Omentum-Cultured 3D-Printed Artificial Trachea: In Vivo Bioreactor. Artif. Cell Nanomedicine, Biotechnol. 46 (Suppl. 3), S1131-S1140. doi:10.1080/ 21691401.2018.1533844

Park, J.-H., Yoon, J.-K., Lee, J. B., Shin, Y. M., Lee, K.-W., Bae, S.-W., et al. (2019). Experimental Tracheal Replacement Using 3-dimensional Bioprinted Artificial Trachea with Autologous Epithelial Cells and Chondrocytes. Sci. Rep. 9, 2103. doi:10.1038/s41598-019-38565-Z

Park, J. H., Hong, J. M., Ju, Y. M., Jung, J. W., Kang, H.-W., Lee, S. J., et al. (2015). A Novel Tissue-Engineered Trachea with a Mechanical Behavior Similar to Native Trachea. Biomaterials 62, 106-115. doi:10.1016/j.biomaterials.2015.05.008

Park, J. Y., Choi, Y.-J., Shim, J.-H., Park, J. H., and Cho, D.-W. (2017). Development of a 3D Cell Printed Structure as an Alternative to Autologs Cartilage for Auricular Reconstruction. J. Biomed. Mater. Res. 105 (5), 1016-1028. doi:10.1002/jbm.b.33639

Parkhouse, N., and Evans, D. (1985). Reconstruction of the Ala of the Nose Using a Composite Free Flap from the Pinna. Br. J. Plast. Surg. 38 (3), 306-313. doi:10.1016/0007-1226(85)90233-4

Patel, J. J., Modes, J. E., Flanagan, C. L., Krebsbach, P. H., Edwards, S. P., and Hollister, S. J. (2015). Dual Delivery of EPO and BMP2 from a Novel Modular Poly- $\mathcal{E}$-Caprolactone Construct to Increase the Bone Formation in Prefabricated Bone Flaps. Tissue Eng. C: Methods 21 (9), 889-897. doi: $10.1089 /$ ten.tec.2014.0643

Pensa, N. W., Curry, A. S., Bonvallet, P. P., Bellis, N. F., Rettig, K. M., Reddy, M. S., et al. (2019). 3D Printed Mesh Reinforcements Enhance the Mechanical Properties of Electrospun Scaffolds. Biomater. Res. 23 (1), 22. doi:10.1186/ s40824-019-0171-0

Penumakala, P. K., Santo, J., and Thomas, A. (2020). A Critical Review on the Fused Deposition Modeling of Thermoplastic Polymer Composites. Composites B: Eng. 201, 108336. doi:10.1016/j.compositesb.2020.108336

Pittenger, M. F., Mackay, A. M., Beck, S. C., Jaiswal, R. K., Douglas, R., Mosca, J. D., et al. (1999). Multilineage Potential of Adult Human Mesenchymal Stem Cells. Science 284 (5411), 143-147. doi:10.1126/ science.284.5411.143

Popescu, D., Zapciu, A., Amza, C., Baciu, F., and Marinescu, R. (2018). FDM Process Parameters Influence over the Mechanical Properties of Polymer Specimens: A Review. Polym. Test. 69, 157-166. doi:10.1016/ j.polymertesting.2018.05.020

Ra, J. C., Shin, I. S., Kim, S. H., Kang, S. K., Kang, B. C., Lee, H. Y., et al. (2011). Safety of Intravenous Infusion of Human Adipose Tissue-Derived Mesenchymal Stem Cells in Animals and Humans. Stem Cell Develop. 20 (8), 1297-1308. doi:10.1089/scd.2010.0466

Rajabi, M., McConnell, M., Cabral, J., and Ali, M. A. (2021). Chitosan Hydrogels in 3D Printing for Biomedical Applications. Carbohydr. Polym. 260, 117768. doi:10.1016/j.carbpol.2021.117768

Rajzer, I., Kurowska, A., Jabłoński, A., Jatteau, S., Śliwka, M., Ziąbka, M., et al. (2018). Layered Gelatin/PLLA Scaffolds Fabricated by Electrospinning and 3D 
Printing- for Nasal Cartilages and Subchondral Bone Reconstruction. Mater. Des. 155 (OCT), 297-306. doi:10.1016/j.matdes.2018.06.012

Rajzer, I., Kurowska, A., Jabłoński, A., Kwiatkowski, R., Piekarczyk, W., Hajduga, M. B., et al. (2020). Scaffolds Modified with Graphene as Future Implants for Nasal Cartilage. J. Mater. Sci. 55, 4030-4042. doi:10.1007/s10853-019-04298-7

Raucci, M. G., D’Amora, U., Ronca, A., Demitri, C., and Ambrosio, L. (2019). Bioactivation Routes of Gelatin-Based Scaffolds to Enhance at Nanoscale Level Bone Tissue Regeneration. Front. Bioeng. Biotechnol. 7, 27. doi:10.3389/ fbioe.2019.00027

Romanazzo, S., Vedicherla, S., Moran, C., and Kelly, D. J. (2017). Meniscus ECMfunctionalised Hydrogels Containing Infrapatellar Fat Pad-derived Stem Cells for Bioprinting of Regionally Defined Meniscal Tissue. J. Tissue Eng. Regen. Med. 12 (3), e1826-e1835. doi:10.1002/term.2602

Rich, J. T., and Gullane, P. J. (2012). Current Concepts in Tracheal Reconstruction. Curr. Opin. Otolaryngol. Head Neck Surg. 20 (4), 246-253. doi:10.1097/ MOO.0b013e328355580e

Rosadi, I., Karina, K., Rosliana, I., Sobariah, S., Afini, I., Widyastuti, T., et al. (2019). In Vitro study of Cartilage Tissue Engineering Using Human Adipose-Derived Stem Cells Induced by Platelet-Rich Plasma and Cultured on Silk Fibroin Scaffold. Stem Cel Res Ther 10 (1), 369. doi:10.1186/s13287-019-1443-2

Rosenzweig, D., Carelli, E., Steffen, T., Jarzem, P., and Haglund, L. (2015). 3DPrinted ABS and PLA Scaffolds for Cartilage and Nucleus Pulposus Tissue Regeneration. Ijms 16 (7), 15118-15135. doi:10.3390/ijms160715118

Ruiz-Cantu, L., Gleadall, A., Faris, C., Segal, J., Shakesheff, K., and Yang, J. (2020). Multi-material 3D Bioprinting of Porous Constructs for Cartilage Regeneration. Mater. Sci. Eng. C 109, 110578. doi:10.1016/j.msec.2019.110578

Schneider, M., Günter, C., and Taubert, A. (2018). Co-Deposition of a Hydrogel/ Calcium Phosphate Hybrid Layer on 3D Printed Poly(Lactic Acid) Scaffolds via Dip Coating: Towards Automated Biomaterials Fabrication. Polymers 10 (3), 275. doi:10.3390/polym 10030275

She, Y., Fan, Z., Wang, L., Li, Y., Sun, W., Tang, H., et al. (2021). 3D Printed Biomimetic PCL Scaffold as Framework Interspersed with Collagen for Long Segment Tracheal Replacement. Front. Cel Dev. Biol. 9, 629796. doi:10.3389/ fcell.2021.629796

Singh, Y. P., Bandyopadhyay, A., and Mandal, B. B. (2019). 3D Bioprinting Using Cross-linker-free Silk-Gelatin Bioink for Cartilage Tissue Engineering. ACS Appl. Mater. Inter. 11 (37), 33684-33696. doi:10.1021/acsami.9b11644

Soltan, N., Ning, L., Mohabatpour, F., Papagerakis, P., and Chen, X. (2019). Printability and Cell Viability in Bioprinting Alginate Dialdehyde-Gelatin Scaffolds. ACS Biomater. Sci. Eng. 5 (6), 2976-2987. doi:10.1021/ acsbiomaterials.9b00167

Song, Y., Yang, Q., Jiang, H., and Dong, W. (2020). Clinical Application of Carving Template with 3D Reconstruction Technique for Personalized and Precise Treatment of Traumatic Ear Defects. J. Craniofac. Surg. publish ahead print 32 (4), 1423-1426. doi:10.1097/SCS.0000000000007166

Strioga, M., Viswanathan, S., Darinskas, A., Slaby, O., and Michalek, J. (2012). Same or Not the Same? Comparison of Adipose Tissue-Derived versus Bone Marrow-Derived Mesenchymal Stem and Stromal Cells. Stem Cell Develop. 21 (14), 2724-2752. doi:10.1089/scd.2011.0722

Sun, Y., You, Y., Jiang, W., Wu, Q., Wang, B., and Dai, K. (2020). Generating Ready-To-Implant Anisotropic Menisci by 3D-Bioprinting Protein-Releasing Cell-Laden Hydrogel-Polymer Composite Scaffold. Appl. Mater. Today 18, 100469. doi:10.1016/j.apmt.2019.100469

Takahashi, A., Matsumoto, H., Nagayama, K., Kitano, M., Hirose, S., Tanaka, H., et al. (2004). Evidence for the Involvement of Double-Strand Breaks in HeatInduced Cell Killing. Cancer Res. 64 (24), 8839-8845. doi:10.1158/00085472.CAN-04-1876

Teramachi, M., Okumura, N., Nakamura, T., Yamamoto, Y., Kiyotani, T., Takimoto, Y., et al. (1997). Intrathoracic Tracheal Reconstruction with a Collagen-Conjugated Prosthesis: Evaluation of the Efficacy of Omental Wrapping. J. Thorac. Cardiovasc. Surg. 113 (4), 701-711. doi:10.1016/S00225223(97)70227-7

Thorne, C. H., Bradley, L. E., Levine, J. P., Hammerschlag, P., and Longaker, M. T. (2001). Auricular Reconstruction: Indications for Autogenous and Prosthetic Techniques. Plast. Reconstr. Surg. 107 (5), 1241-1251. doi:10.1097/00006534200104150-00024

Unagolla, J. M., and Jayasuriya, A. C. (2020). Hydrogel-based 3D Bioprinting: A Comprehensive Review on Cell-Laden Hydrogels, Bioink Formulations, and
Future Perspectives. Appl. Mater. Today 18, 100479. doi:10.1016/ j.apmt.2019.100479

Van den Eynde, M., and Van Puyvelde, P. (2017). "3D Printing of Poly(lactic Acid)," in Industrial Applications of Poly(lactic Acid), 282, 139-158. doi:10.1007/12_2017_28

Virk, J. S., Zhang, H., Nouraei, R., and Sandhu, G. (2017). Prosthetic Reconstruction of the Trachea: A Historical Perspective. Wjcc 5 (4), 128-133. doi:10.12998/wjcc.v5.i4.128

Visscher, D. O., Gleadall, A., Buskermolen, J. K., Burla, F., Segal, J., Koenderink, G. H., et al. (2019). Design and Fabrication of a Hybrid Alginate Hydrogel/poly $(\varepsilon-$ caprolactone) Mold for Auricular Cartilage Reconstruction. J. Biomed. Mater. Res. 107 (5), 1711-1721. doi:10.1002/jbm.b.34264

Vuyk, H. D., and Adamson, P. A. (1998). Biomaterials in Rhinoplasty. Clin. Otolaryngol. 23 (3), 209-217. doi:10.1046/j.1365-2273.1998.00133.x

Wang, P., Auhl, D., Uhlmann, E., Gerlitzky, G., and Wagner, M. H. (2019). Rheological and Mechanical Gradient Properties of Polyurethane Elastomers for 3D-Printing with Reactive Additives. Appl. Rheology 29 (1), 162-172. doi:10.1515/arh-2019-0014

Wang, Q., Han, G., Yan, S., and Zhang, Q. (2019). 3D Printing of Silk Fibroin for Biomedical Applications. Materials 12 (3), 504. doi:10.3390/ma12030504

Wang, R., Yang, R., and Yang, F. (2015). Production of Bamboo Fiber Reinforced Fibrillated Poly(lactic Acid) (PLA) Material Obtained by a Papermaking Process. J. Wuhan Univ. Technol.-Mat. Sci. Edit. 30 (2), 429-432. doi:10.1007/s11595-015-1165-y

Wang, L., Fang, M., Xia, Y., Hou, J., Nan, X., Zhao, B., et al. (2020). Preparation and Biological Properties of Silk Fibroin/nano-Hydroxyapatite/graphene Oxide Scaffolds with an Oriented Channel-like Structure. RSC Adv. 10 (17), 10118-10128. doi:10.1039/c9ra09710d

Wang, Y.-H., Wang, D.-R., Guo, Y.-C., Liu, J.-Y., and Pan, J. (2020). The Application of Bone Marrow Mesenchymal Stem Cells and Biomaterials in Skeletal Muscle Regeneration. Regenerative Ther. 15, 285-294. doi:10.1016/ j.reth.2020.11.002

Wang, Y.-J., Jeng, U.-S., and Hsu, S.-h. (2018). Biodegradable Water-Based Polyurethane Shape Memory Elastomers for Bone Tissue Engineering. ACS Biomater. Sci. Eng. 4 (4), 1397-1406. doi:10.1021/acsbiomaterials.8b00091

Wei, P., Xu, Y., Gu, Y., Yao, Q., Li, J., and Wang, L. (2020). IGF-1-releasing PLGA Nanoparticles Modified 3D Printed PCL Scaffolds for Cartilage Tissue Engineering. Drug Deliv. 27 (1), 1106-1114. doi:10.1080/ 10717544.2020.1797239

Wei, X., Liu, C., Wang, Z., and Luo, Y. (2020). 3D Printed Core-Shell Hydrogel Fiber Scaffolds with NIR-Triggered Drug Release for Localized Therapy of Breast Cancer. Int. J. Pharmaceutics 580, 119219. doi:10.1016/ j.ijpharm.2020.119219

Wiggenhauser, P. S., Schwarz, S., Koerber, L., Hoffmann, T. K., and Rotter, N. (2019). Addition of Decellularized Extracellular Matrix of Porcine Nasal Cartilage Improves Cartilage Regenerative Capacities of PCL-Based Scaffolds In Vitro. J. Mater. Sci. Mater. Med. 30 (11), 121. doi:10.1007/s10856-019-6323-x

Wu, J.-J., Huang, L.-M., Zhao, Q., and Xie, T. (2018). 4D Printing: History and Recent Progress. Chin. J. Polym. Sci. 36 (5), 563-575. doi:10.1007/s10118-0182089-8

Xia, D., Jin, D., Wang, Q., Gao, M., Zhang, J., Zhang, H., et al. (2019). Tissueengineered Trachea from a 3D-printed Scaffold Enhances Whole-segment Tracheal Repair in a Goat Model. J. Tissue Eng. Regen. Med. 13 (4), 694-703. doi:10.1002/term.2828

Xia, H., Zhao, D., Zhu, H., Hua, Y., Xiao, K., Xu, Y., et al. (2018). Lyophilized Scaffolds Fabricated from 3D-Printed Photocurable Natural Hydrogel for Cartilage Regeneration. ACS Appl. Mater. Inter. 10 (37), 31704-31715. doi: $10.1021 /$ acsami.8b10926

Xiao, J., and Gao, Y. (2017). The Manufacture of 3D Printing of Medical Grade TPU. Prog. Addit Manuf 2 (3), 117-123. doi:10.1007/s40964-0170023-1

Xu, Y., Peng, J., Richards, G., Lu, S., and Eglin, D. (2019). Optimization of Electrospray Fabrication of Stem Cell-Embedded Alginate-Gelatin Microspheres and Their Assembly in 3D-Printed Poly( $\varepsilon$-Caprolactone) Scaffold for Cartilage Tissue Engineering. J. Orthopaedic Translation 18, 128-141. doi:10.1016/j.jot.2019.05.003

Yamada, A. (2018). Autologous Rib Microtia Construction. Facial Plast. Surg. Clin. North America 26 (1), 41-55. doi:10.1016/j.fsc.2017.09.006 
Yang, Y., Yang, G., Song, Y., Xu, Y., Zhao, S., and Zhang, W. (2019). 3D Bioprinted Integrated Osteochondral Scaffold-Mediated Repair of Articular Cartilage Defects in the Rabbit Knee. J. Med. Biol. Eng. 40 (1), 71-81. doi:10.1007/ s40846-019-00481-y

Younis, I., Gault, D., Sabbagh, W., and Kang, N. V. (2010). Patient Satisfaction and Aesthetic Outcomes after Ear Reconstruction with a Branemark-type, BoneAnchored, Ear Prosthesis: a 16 Year Review. J. Plast. Reconstr. Aesthet. Surg. 63 (10), 1650-1655. doi:10.1016/j.bjps.2009.10.004

Yu, Y. S., Ahn, C. B., Son, K. H., and Lee, J. W. (2021). Motility Improvement of Biomimetic Trachea Scaffold via Hybrid 3D-Bioprinting Technology. Polymers (Basel) 13 (6). doi:10.3390/polym1306010.3390/polym 13060971

Zafar, B., Mottaghitalab, F., Shahosseini, Z., Negahdari, B., and Farokhi, M. (2020). Silk Fibroin/alumina Nanoparticle Scaffold Using for Osteogenic Differentiation of Rabbit Adipose-Derived Stem Cells. Materialia 9, 100518. doi:10.1016/j.mtla.2019.100518

Zaim, M., Karaman, S., Cetin, G., and Isik, S. (2012). Donor Age and Long-Term Culture Affect Differentiation and Proliferation of Human Bone Marrow Mesenchymal Stem Cells. Ann. Hematol. 91 (8), 1175-1186. doi:10.1007/ s00277-012-1438-x

Zhang, B., Guo, L., Chen, H., Ventikos, Y., Narayan, R. J., and Huang, J. (2020). Finite Element Evaluations of the Mechanical Properties of Polycaprolactone/ hydroxyapatite Scaffolds by Direct Ink Writing: Effects of Pore Geometry. J. Mech. Behav. Biomed. Mater. 104, 103665. doi:10.1016/j.jmbbm.2020.103665

Zhang, B., and Song, J. (2018). 3D-Printed Biomaterials for Guided Tissue Regeneration. Small Methods 2 (9), 1700306. doi:10.1002/smtd.201700306

Zhang, F., You, X., Dou, H., Liu, Z., Zuo, B., and Zhang, X. (2015). Facile Fabrication of Robust Silk Nanofibril Films via Direct Dissolution of Silk in CaCl2-Formic Acid Solution. ACS Appl. Mater. Inter. 7 (5), 3352-3361. doi:10.1021/am508319h

Zhang, J., Wehrle, E., Vetsch, J. R., Paul, G. R., Rubert, M., and Müller, R. (2019). Alginate Dependent Changes of Physical Properties in 3D Bioprinted CellLaden Porous Scaffolds Affect Cell Viability and Cell Morphology. Biomed. Mater. 14 (6), 065009. doi:10.1088/1748-605X/ab3c74

Zhang, Z.-Z., Jiang, D., Ding, J.-X., Wang, S.-J., Zhang, L., Zhang, J.-Y., et al. (2016). Role of Scaffold Mean Pore Size in Meniscus Regeneration. Acta Biomater. 43, 314-326. doi:10.1016/j.actbio.2016.07.050

Zhang, Z.-Z., Jiang, D., Ding, J.-X., Wang, S.-J., Zhang, L., Zhang, J.-Y., et al. (2016). Role of Scaffold Mean Pore Size in Meniscus Regeneration. Acta Biomater. 43, 314-326. doi:10.1016/j.actbio.2016.07.050

Zhang, Z.-Z., Wang, S.-J., Zhang, J.-Y., Jiang, W.-B., Huang, A.-B., Qi, Y.-S., et al. (2017). 3D-Printed Poly( $\varepsilon$-Caprolactone) Scaffold Augmented with
Mesenchymal Stem Cells for Total Meniscal Substitution: A 12- and 24Week Animal Study in a Rabbit Model. Am. J. Sports Med. 45 (7), 1497-1511. doi:10.1177/0363546517691513

Zhao, C. Q., Liu, W. G., Xu, Z. Y., Li, J. G., Huang, T. T., Lu, Y. J., et al. (2020). Chitosan Ducts Fabricated by Extrusion-Based 3D Printing for Soft-Tissue Engineering. Carbohydr. Polym. 236, 116058. doi:10.1016/ j.carbpol.2020.116058

Zhao, G., Cui, R., Chen, Y., Zhou, S., Wang, C., Hu, Z., et al. (2020). 3D Printing of Well Dispersed Electrospun PLGA Fiber Toughened Calcium Phosphate Scaffolds for Osteoanagenesis. J. Bionic Eng. 17 (4), 652-668. doi:10.1007/ s42235-020-0051-2

Zhou, G., Jiang, H., Yin, Z., Liu, Y., Zhang, Q., Zhang, C., et al. (2018). In Vitro Regeneration of Patient-specific Ear-Shaped Cartilage and its First Clinical Application for Auricular Reconstruction. EBioMedicine 28, 287-302. doi:10.1016/j.ebiom.2018.01.011

Zopf, D. A., Flanagan, C. L., Mitsak, A. G., Brennan, J. R., and Hollister, S. J. (2018). Pore Architecture Effects on Chondrogenic Potential of Patient-specific 3-dimensionally Printed Porous Tissue Bioscaffolds for Auricular Tissue Engineering. Int. J. Pediatr. Otorhinolaryngol. 114, 170-174. doi:10.1016/j.ijporl.2018.07.033

Zopf, D. A., Mitsak, A. G., Flanagan, C. L., Wheeler, M., Green, G. E., and Hollister, S. J. (2015). Computer Aided-Designed, 3-dimensionally Printed Porous Tissue Bioscaffolds for Craniofacial Soft Tissue Reconstruction. Otolaryngol. Head Neck Surg. 152 (1), 57-62. doi:10.1177/0194599814552065

Conflict of Interest: The authors declare that the research was conducted in the absence of any commercial or financial relationships that could be construed as a potential conflict of interest.

Publisher's Note: All claims expressed in this article are solely those of the authors and do not necessarily represent those of their affiliated organizations, or those of the publisher, the editors and the reviewers. Any product that may be evaluated in this article, or claim that may be made by its manufacturer, is not guaranteed or endorsed by the publisher.

Copyright (c) 2022 Wang, Wang, Liu, Liu, Li, Zhu, Ren, Wang, Liu, Li, Jia, Wang and Wang. This is an open-access article distributed under the terms of the Creative Commons Attribution License (CC BY). The use, distribution or reproduction in other forums is permitted, provided the original author(s) and the copyright owner(s) are credited and that the original publication in this journal is cited, in accordance with accepted academic practice. No use, distribution or reproduction is permitted which does not comply with these terms. 